\title{
EL ARQUITECTO BENEDICTINO FRAY PLACIDO CAAMIÑA Y SU PROYECTO DE CASAS CONSISTORIALES Y CARCELES PARA LA CIUDAD DE FERROL (1791)
}

\author{
p.or \\ ALFREDO VIGO TRASANCOS \\ «Parecerá acaso el edificio que se registra en esos famo- \\ sos planos a algunos, sin duda destituidos del bello gus- \\ to, que es su obra demasiado asunto para Ferrol; pero \\ sepan éstos que los edificios públicos deben ser hermo- \\ sos y autorizados, supuesto que su ornato y magnitud es \\ el interés de la misma ciudad, villa o lugar donde se \\ construyen... Quien más ennoblece los pueblos son, digo, \\ sus suntuosos y magnificos edificios, cuya memoria, aun \\ después de su ruina, dura en los futuros siglos y cons- \\ tituye a sus fabricadores dignos de una eterna fama.» \\ (E.M. Alvarez Caballero, 1786)
}

Aunque desde el punto de vista de la proyección urbana no se puede negar que el Nuevo Ferrol ${ }^{1}$ fue una de las realizaciones más destacadas y modélicas de cuantas se ejecutaron en la España de las Luces ${ }^{2}$, no por ello debe aceptarse que todo en la «nueva ciudad» estaba conformado y resuelto de una manera que pudiera considerarse ejemplar en términos absolutos. Acaso lo fuese, en líneas generales, su traza rectangular perfectamente regular y organizada en torno a dos plazas simétricas, asimismo su buscada

\footnotetext{
Al respecto vid. TARRAGO CID-VIGO TRASANCOS-RODRIGUEZ VILLASANTE y más especialmente VIGO TRASANCOS (1984), 135-170.

${ }^{2}$ Como síntesis de más interés pueden consultarse CHUECA GOITIA; SAMBRICIO (1982) y sobre todo SAMBRICIO (1991).
}

"CUADERnOS DE eStudios GALLEGoS", Tomo XLII, Fascículo 107, Santiago 1995. 
proximidad respecto al Arsenal Militar al que se hallaba vinculada, o incluso el afán puesto en que todas las calles y manzanas que conformaban su tejido fuesen idénticas en su forma, configuración y amplitud. Pero tanto rigor homogeneizante, tal vez extremado, lo que ponía de manifiesto era, sobre todo, el deseo de crear un núcleo de población práctico, igualitario y fácil de ejecutar, antes que la elaboración de un plan de ciudad en toda regla que diese forma y cabida a una auténtica «Capital» como era el caso ferrolano desde que, a partir de 1726, se había convertido a la vieja villa marinera en sede del Departamento Marítimo del Norte, uno da los tres en que se había dividido el territorio costero de la Península ${ }^{3}$.

Quizá por ello no deja de resultar sorprendente que lo que con el tiempo habría de denominarse «Barrio de la Magdalena» fuese tan distinto en su configuración y resultados al previsto en la ciudad nueva de San Carlos en la Isla de León que estaba destinada a ser, ciertamente, la Capital Departamental del Sur. Porque en el ejemplo gaditano, que fue elaborado en lo básico por el ingeniero Vicente Imperial Digueri en $1785^{4}$, siempre predominó, en efecto, el deseo de levantar una auténtica ciudad ejemplar y representativa, lo que explica que no sólo tuviese una forma clara y precisa y una destacada singularidad, sino también unos criterios jerárquicos muy estrictos que tanto dominaban en el plan viario como en el deseo de implicar los «monumentos» arquitectónicos en su propia trama urbanística. Eso es lo que explica, de hecho, que la Capital del Estrecho disponga primeramente de un centro rector en la plaza que aparece rodeada de las principales construcciones oficiales (Iglesia Parroquial, Casa del Capitán General, Intendencia, Tesorería y Cuartel de Guardias-Marinas), luego de un amplio sector destinado a zona de residencia, en tercer lugar de una clara zona perimétrica en la que de nuevo se abren varias plazas secundarias que estaban presididas por cuarteles y un hospital; y por último que todo el plan quedase vertebrado por tres amplias calles dispuestas en cruz que convergían en el centro de la plaza rectora.

\footnotetext{
${ }^{3} \mathrm{El}$ nombramiento tuvo lugar en el reinado de Felipe $\mathrm{V}$ y como consecuencia de ello la «villa», que hasta entonces había pertenecido a la Casa de Andrade y luego a la de Lemos, pasó a depender de la Jurisdicción Real en 1733. Vid. MONTERO AROSTEGUI, 43. Cito por la edición publicada en Puentedeume en 1972. No obstante, el título oficial de «ciudad» no le fue concedido hasta el reinado de Isabel II por Real Decreto de 13 de Octubre de 1858.

${ }^{4}$ Sobre el plan de ciudad nueva que se proyectó para la Capital del Estrecho es básica la consulta del excelente trabajo de TORREJON CHAVES. Especialmente pp. 73-132.
} 
Así pues, no hay duda que en el ejemplo gaditano la ciudad se concibió como un centro aglutinador de todos los servicios y, en definitiva, como una auténtica «Capital» en el sentido pleno del término capaz de aunar «función»y «representación». Mientras que el Nuevo Ferrol, tal vez por haber sido planeado con anterioridad y con otros condicionantes previos muy distintos ${ }^{5}$, nunca pasó de proyectarse como un simple barrio dormitorio o, si se prefiere, como un núcleo meramente residencial que, todo lo más, por disponer en los extremos de dos plazas destinadas a mercados públicos, también estaba previsto que tuviese un cometido de tipo comercial siquiera de carácter puramente interno.

En todo caso, a la vista de las circunstancias que se han señalado lo que resulta un hecho difícil de contestar es que, desde que se configuró en $1762^{6}$, el Ferrol Nuevo nunca estuvo pensado para acoger en su interior ningún tipo de construcción relacionable con los poderes públicos. Hasta el punto que, tanto la Iglesia Parroquial de San Julián, el Convento de San Francisco, el Hospital de Caridad, como todas las edificaciones vinculables con lo militar o bien se levantaron o se pensaron disponer en el entorno inmediato de la Ciudad Nueva (Casa del Comandate General, Cuartel de Guardias-Marinas, Cuartel de Brigadas, Contaduría de Marina etc.) o, por el contrario, prefirieron hacerlo incluso en zonas que se encontraban francamente alejadas como fue el caso del Cuartel de Batallones, de la Intendencia, de la Capilla Castrense de San Fernando o del propio Hospital de Marina que se construyeron, ciertamente, en las inmediaciones del poblado de Esteiro. Por tanto, debe quedar claro que el Ferrol dieciochesco sólo se planificó como un barrio residencial al servicio del Arsenal sin ninguna arquitectura representativa inmersa en su tejido ${ }^{7}$. De ahí la im-

\footnotetext{
${ }^{5}$ De hecho, los primeros proyectos fueron configurados a partir de 1751 al poco de decidirse el traslado del Arsenal Militar de la villa de La Graña a la de Ferrol, sin duda mucho más ventajosa para acojer unas instalaciones de estas características. Sin embargo, el comienzo de las obras se pospuso por problemas de orden económico hasta 1761,10 que obligó a que en el intermedio los nuevos pobladores tuviesen que subsistir en condiciones bastante penosas en el poblado de «barracas» que se habilitó apresuradamente en el monte de Esteiro inmediato al Astillero Real. Vid. VIGO TRASANCOS (1984), 121 134 y 144.

${ }^{6} \mathrm{~A}$ esta fecha corresponde, en efecto, la traza definitiva elaborada por Jorge Juan. Vid. VIGO TRASANCOS (1984), 150-151.

${ }^{7} \mathrm{La}$ única excepción que cabe señalar fue la construcción tardía de la modesta Capilla de la Virgen de los Dolores en el sector oriental de la plaza de su mismo nombre que hoy se conoce como del Marqués de Amboage. Se comenzó a levantar en 1771 sobre planos
}

"CUADERNOS DE ESTUdIOS GALlEGOS", Tomo XLII, Fascículo 107, Santiago 1995. 
portancia que tuvo en su momento la decisión del Alcalde Mayor D. Eugenio Manuel Alvarez Caballero ${ }^{8}$ de pretender erigir en el sector norte de la plaza de los Dolores (Fig. 1), la más occidental del Barrio de la Magdalena', el edificio más representativo que una ciudad podía levantar, cual era el caso del propio Consistorio que habría de albergar también la Cárcel Pública y salas asimismo para la administración de justicia (Fig. 2).

\section{EL PROYECTO DE CASAS CONSISTORIALES DEL INGENIE- RO MILITAR DIONISIO SANCHEZ DE AGUILERA (1786)}

Tal decisión, que debe interpretarse como una iniciativa personal del propio Alcalde, es sabido que fue tomada en $1786^{10}$ aprovechándose la circunstancia de que se habían empezado a abrir, poco antes, los desmontes necesarios para convertir la plaza de los Dolores en un foro público adecuado para desempañar la actividad comercial (Fig. 3). Su área, en efecto, se había comenzado a preparar en $1784^{11}$; y desde entonces, puesto que la ciudad carecía de un edificio digno para Consistorio y Cárceles, el Alcalde mantuvo la esperanza de que el nuevo ámbito fuese el lugar en donde se levantase la nueva construcción. Sabemos que, para ello, en la fecha que se ha indicado en primer lugar, había solicitado planos al ingeniero militar

del arquitecto académico Antonio de Bada y Navajas; no obstante su conclusión no tuvo lugar hasta 1780 aproximadamente. Más información en MONTERO AROSTEGUI, 259262; VIGO TRASANCOS (1984), 229-230 y GONZÁLEZ RODRIGUEZ, 663-691. Posteriormente, ya a comienzos del siglo XIX, se levantaron en la actual Plaza de Armas, la más oriental de la Ciudad Nueva, la Capilla de la Virgen del Carmen y, en el centro, la Fuente-Obelisco de Churruca que hoy se encuentra muy transformada en las proximidades de los Jardines de Herrera.

${ }^{8}$ Aunque son muy pocos los datos que poseemos respecto a su figura y personalidad, al menos se puede afirmar que fue nombrado por Carlos III Alcalde Mayor y Corregidor de Ferrol el 15 de Abril de 1783 permaneciendo en el cargo hasta 1787. Era abogado de los Reales Consejos. Vid. MONTERO AROSTEGUI, 194.

${ }^{9}$ Tal como ya se señaló la mencionada plaza es la que hoy lleva el nombre de Marqués de Amboage.

${ }^{10}$ En concreto el 4 de Noviembre de 1786. Vid. MONTERO AROSTEGUI, 197.

"MONTERO AROSTEGUI, 227. Más información puede consultarse en VIGO TRASANCOS (1984), 162-164.

"CUADERnOS DE ESTUdios GALLEGOS", Tomo XLII, Fascículo 107, Santiago 1995. 


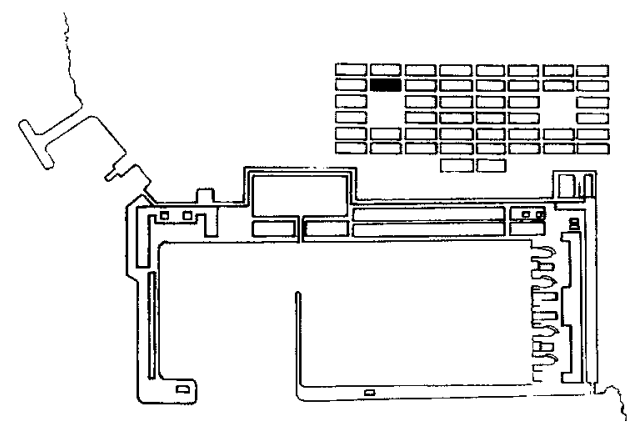

Fig. 1.- Plano del Arsenal y del Nuevo Ferrol con el emplazamiento de las Casas Consistoriales y Cárceles en la Plaza de los Dolores (dibujo de Vicente Vigo).

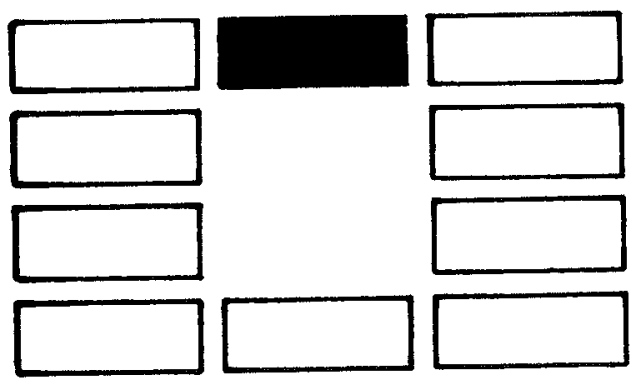

Fig. 2.- Localización de las Casas Consistoriales y Cárceles en la Plaza de los Dolores, hoy del Marqués de Amboage (dibujo de Vicente Vigo).

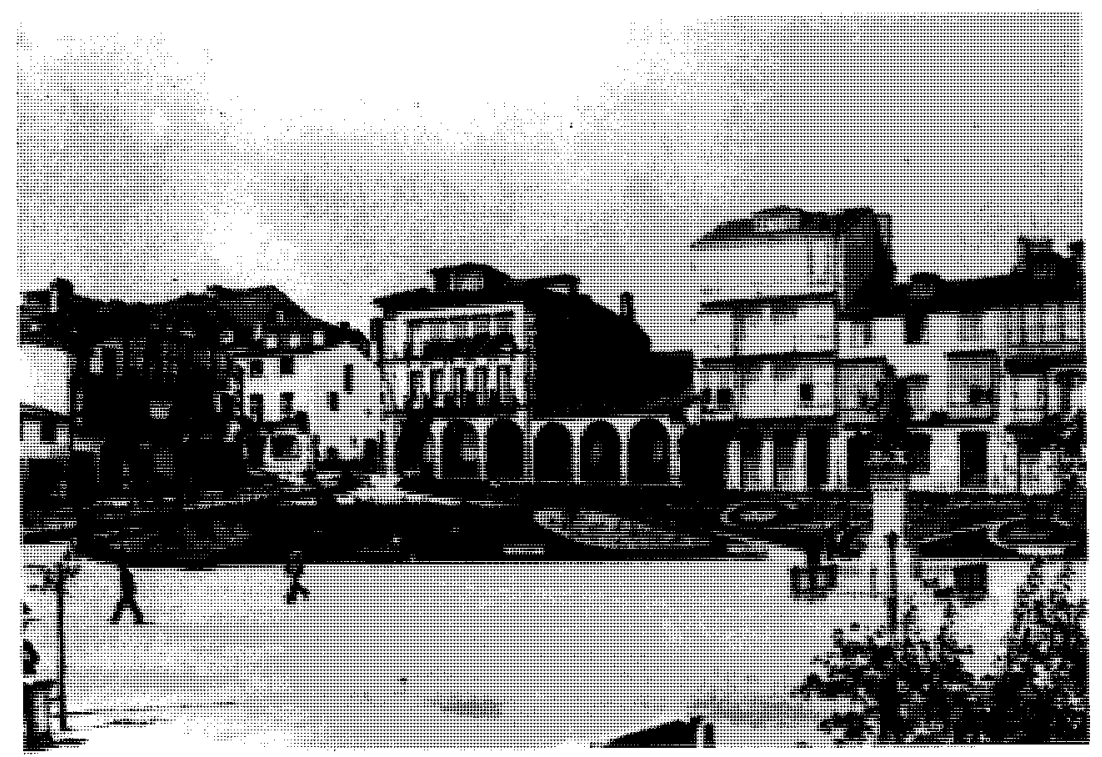

Fig. 3.- Vista parcial de la Plaza de los Dolores a principios de siglo. Se aprecia en uno de sus ángulos la casa porticada del Sr. García Fernández. 
Dionisio Sánchez de Aguilera ${ }^{12}$ que era, por entonces, Sargento Mayor de la Plaza y una de las personas más eminentes que en el campo de la arquitectura residía en la Capital del Departamento ${ }^{13}$. Así que, una vez que estuvieron delineados, lo único que faltaba por alcanzar era que recibiesen primeramente la aprobación del Concejo y, conseguido esto, a continuación el parabién del propio Rey toda vez que había sido él quien había concedido a la ciudad, por la vía reservada de Marina, la ampliación del arbitrio ${ }^{14}$ que, años antes, se había aplicado para erigir distintas obras de carácter público ${ }^{15}$.

De todo esto, que sepamos, no cabe dudar que se consiguió la aprobación del Concejo ya que consta en Acta Municipal del 4 de Noviembre de $1786^{16}$. Nada se sabe, en cambio, de la decisión que correspondía tomar al Rey. En todo caso, si entonces el proyecto de Casa Consistorial y Cárcel elaborado por Dionisio Sánchez Aguilera no llegó a prosperar pienso que debe atribuirse no ya a una posible negativa regia, como a la marcha de la ciudad del principal valedor del proyecto D. Eugenio Manuel Alvarez Caba-

\footnotetext{
${ }^{12}$ MONTERO AROSTEGUI, 198. El texto recogido por el autor mencionado dice lo siguiente: "Supliqué con las veras del mayor encarecimiento al Teniente Coronel de Ingenieros D. Dionisio Sánchez de Aguilera, Caballero del hábito de Santiago y Sargento Mayor de la Plaza, se sirviese levantar planos correspondientes a la insinuada nueva Cárcel y Casa Consistorial; encontré en el corazón de este noble héroe aquel siempre laudable celo público... y baste sólo decir que apenas abri los labios...cuando ya el lapicero estaba sobre el papel para la extensión de los que presento a la vista de este ilustre congreso".

${ }^{13}$ No son muchos los datos que sobre él poseemos; pero son de interés los que aparecen mencionados en MONTERO AROSTEGUI; CAPEL et al., 429-430; VIGO TRASANCOS (1984),250-253, 255-258 y 269-276; RODRIGUEZ-VILLASANTE, 127 128; SORALUCE BLOND, 131-136; GARCIA-ALCAÑIZ (1986),II, 811 y GARCIAALCAÑIZ (1989), 220. En Ferrol fue el artífice del Hospital de Caridad y de su Capilla, de la Escuela de Gramática y del grueso del diseño del Recinto Fortificado de la Plaza. Había nacido en Andalucía y su presencia en Ferrol consta desde 1768. Murió el la Ciudad Departamental el 20 de Abril de 1811 siendo entonces Coronel.

${ }^{14}$ El Rey, en efecto, se dignó ampliar el arbitrio por R.O. de 28 de Mayo de 1768. Para su administración se creó entonces una Junta especial. Vid. MONTERO AROSTEGUI, 193.

${ }^{15}$ Por R.O. de 22 de Mayo de 1765 se impuso ciertamente el arbitrio de 4 maravedís en azumbre de vino para la construcción de la nueva Iglesia Parroquial de San Julián. Cfr. MONTERO AROSTEGUI, 192.

${ }^{16}$ Cit. por MONTERO AROSTEGUI, 200. El acta aprobatoria fue firmada por D. Eugenio Manuel Alvarez Caballero, D. Josef Benito Suárez, D. Jaime Salomón y D. Josef de Benavides.
}

"CUADERNOS DE EStUdios GALLEGOS", Tomo XLII, Fascículo 107, Santiago 1995. 
llero que, en efecto, partió de Ferrol para Madrid en 1787 para tomar posesión de su nuevo cargo vinculado a la carrera jurídica ${ }^{17}$.

Por consiguiente esta fue la razón de que el plan de Aguilera no se llevase a buen fin y es de lamentar, además, que los planos que entonces se elaboraron tampoco hayan aperecido hasta la fecha. Sólo sabemos de ellos que contemplaban un proyecto grandioso que pretendía ocupar la totalidad del sector norte de la plaza de los Dolores y que el edificio, junto a Consistoriales y Cárceles, estaba previsto asimismo para acoger el Archivo del Escribano, la Audiencia, el Peso Real y Casa incluso para el Corregidor "todo unido del mejor gusto y magnificencia»" ${ }^{18}$. Pero en cuanto a forma, disposición y morfología externa nada se puede afirmar con certeza dadas las circunstancias que se han señalado.

El historiador ferrolano Montero Aróstegui menciona, sin embargo, que la idea general que imperaba en el proyecto de Aguilera era la de un edificio que habría de estar todo él levantado sobre pórticos ${ }^{19}$. Dice incluso que esta

${ }^{17}$ VIGO TRASANCOS (1984), 255. Posteriormente, ya en Madrid, consiguió que se creasen para el gobierno de las villas de Ferrol y La Graña 6 oficios de regidores trienales por R.O. de 28 de Abril de 1788. Lo puso en conocimiento de la Municipalidad por carta del mes de Mayo de ese mismo año. Vid. MONTERO AROSTEGUI, 201.

${ }^{18}$ Así al menos se expresa Sánchez Aguilera en carta del 26 de Julio de 1790 dirigidạ a la Corporación molesto porque su proyecto fuese al fin desechado y encargado a otro arquitecto que tuvo que venir de fuera: "proyecto, planos y cálculo de la Casa de Ayuntamiento, archivo de escribano, audiencia, cárcel pública, peso real y casa del corregidor en la Plaza de los Dolores, todo unido del mejor gusto y magnificencia, con atención a los grandes edificios que hay en el Departamento, que diese honor a la villa y ocupase el frente de la plaza... Inmediatamente di principio trabajando dia y noche en los muchos planos, perfiles y vistas, fachadas y cálculos...Al fin hice un proyecto que presentado en el Ayuntamiento el día del Rey 4 de Noviembre de 1786 contó con la aprovación del respetable magistrado». Archivo Municipal de Ferrol (A.M.F.): Actas de la Junta de Arbitrios, Libro 3, 1790-93, fols. 48-50.

${ }^{19}$ La solución de un Ayuntamiento porticado es fácil de asumir en estas fechas teniendo en cuenta que impera en construcciones concejiles de finales del siglo XVIII y principios del siglo XIX. Son bien expresivas las de los Ayuntamientos norteños de San Sebastián, Vitoria, Bilbao, Villafranca de Ordicia, Tafalla, etc.. No obstante, no debe olvidarse que fue un recurso muy utilizado en los Consistorios barrocos (Salamanca) y también en la gran mayoría de las Consistoriales de la segunda mitad del siglo XIX (Las Palmas, Gijón, etc.). En Galicia no faltan ejemplos bien significativos de las tres épocas; baste recordar el de Lugo de Lucas Ferro Caaveiro, el proyectado para Santiago por el mismo autor, el definitivo de Santiago debido a Carlos Lemaur y los tres que se elaboraron para la Coruña debidos a las autorías respectivas de Fernando Domínguez Romay, Faustino Domínguez Domínguez y Pedro Mariño. Sobre el caso gallego vid. CHAMOSO LAMAS, 28 y ss; ORTEGA ROMERO (1966); VIGO TRASANCOS (1992,I); VIGO TRASANCOS (1995), 100-104; MARTINEZ SUAREZ y FERNANDEZ FERNANDEZ, 74 y ss.

"CUADERNOS DE ESTUdios GALlEGOS", Tomo XLII, Fascículo 107, Santiago 1995. 
idea asoportalada era algo que el Ayuntamiento pensaba también aplicar a todos los frentes de la plaza ${ }^{20}$ buscando sin duda la conformación de una especie de "plaza mayor» al estilo de las muchas que entonces se habían levantado en distintos puntos de la geografía peninsular ${ }^{21} \mathrm{y}$, tiempo después, incluso en alguna ciudad gallega como fue el caso de la de María Pita en La Coruña ${ }^{22}$. No obstante, respecto a esto último debe señalarse que se trata, sin duda, de una información errónea del eminente historiador decimonónico ya que, como se puede constatar de la visión de la cartografia dieciochesca ferrolana, para la altura de los años 1784 y 1786 tres de los cierres de la plaza de los Dolores estaban ya edificados enteramente y ninguno, por cierto, en su zona inferior disponía de pórtico alguno que hubiera justificado la idea señalada de «plaza mayor» ${ }^{23}$. Además, que la información comentada por Aróstegui es equivocada, se vuelve a constatar al comprobar la propia descripción que del plan para Ayuntamiento hizo en su momento el propio Sánchez de Aguilera que, en efecto, menciona la proyección de un edificio de usos múltiples, pero en absoluto de un plan ordenador y porticado para toda la plaza ${ }^{24}$. Por consiguiente, nada hay de cierto en la opinión de Montero Aróstegui; sólo que el proyecto de Casas Consistoriales ideado por Aguilera era grandioso, acaso con pórticos en su planta inferior, aunque pensado exclusivamente para ocupar el solar libre que quedaba en el sector septentrional de la plaza susodicha.

\section{EL PROYECTO DE FRAY PLACIDO CAAMIÑA (1791)}

Ahora bien, que el proyecto de Consistorio y Cárceles redactado por Dionisio Sánchez de Aguilera no llegase a prosperar por la marcha a Madrid de Eugenio Manuel Alvarez Caballero, no quiere decir que la Corporación de Ferrol hubiese abandonado la idea de levantar, aunque en otro momento más oportuno, un edificio adecuado para representar a la Ciudad

\footnotetext{
${ }^{20}$ MONTERO AROSTEGUI, 227.

${ }^{21}$ Sobre este tipo de plazas tan características del urbanismo español es de interés la consulta de BONET CORREA y asimismo de NAVASCUES PALACIO $(1993,1)$.

${ }^{22}$ Respecto a la plaza coruñesa vid. MARTINEZ SUAREZ.

${ }^{23}$ Vid. ilustraciones en VIGO TRASANCOS (1984), 65, 120 y 125. Los planos a los que me refiero fueron elaborados por Julián Sánchez Bort, Sánchez Aguilera y Antonio López Sopeña en 1765, 1774 y 1786 respectivamente.

${ }^{24} \mathrm{Cfr}$. nota 18.
}

"CUADERNOS DE ESTUdios GALleGOS", Tomo XLII, Fascículo 107, Santiago 1995. 
en el mismo lugar que, desde el principio, se había previsto. Y tanto es así que, poco tiempo después, el 4 de Mayo de $1790^{25}$, los miembros que formaban parte de la Junta de Arbitrios tomaban la determinación de encargar a dos de sus miembros, al Marqués de San Saturnino y a D. Juan Caamaño ${ }^{26}$ que eran regidores electos de la ciudad desde el 8 de Abril de $1789^{27}$, la búsqueda de "facultativo ynteligente que instruido del terreno que debe ser en la plaza de los Dolores, costo de materiales y medio según se piensa, forme según la idea que se le de el plano de dicha obra y su presupuesto y de echo se de cuenta para su aprobación $»^{28}$.

Ante tales circunstancias, no llega a entenderse del todo el por qué no se asumió para ejecutar el plan ya elaborado por el mencionado Aguilera, entre otras cosas porque estaba ya delineado, aprobado asimismo por la Junta anterior y era, además, obra magnífica que había sido diseñada por un eminente arquitecto local. Se ve, por tanto, que desaparecido de la ciudad su principal valedor, la nueva Junta prefirió rechazarlo y comisionar a los regidores mentados para que buscasen otro «facultativo» que plantease otra propuesta evidentemente distinta. Y así, en efecto, en nueva reunión de la Junta de Arbitrios celebrada el 28 de Junio de 1790 se menciona expresamente que, como resultado de las gestiones hechas por los comisionados, había concurrido a la villa el padre Fray Plácido Caamiña «del Orden de San Benito morador en el convento de la ciudad de Santiago» para reconocer el terreno de la plaza de los Dolores «a la parte superior» y poder así proceder a la ejecución de los planos que se le habían solicitado ${ }^{29}$; lo que ciertamente hizo y presentó a la Corporación el 13 de Enero de 1791, aunque no consiguieron ser aprobados por considerarse que el nuevo edificio conllevaba el gasto de un presupuesto excesivamente «exorvitante» que alcanzaba la cifra estimada de 1.748 .319 reales $^{30}$.

\footnotetext{
${ }^{25}$ A.M.F.: Actas de la Junta de Arbitrios. Libro 3, 1790-93, fol. 5.

${ }^{26}$ Cierta información sobre los Caamaño de Ferrol puede encontrarse en CRESPO POZO, II, 241-251. El 28 de Diciembre de 1797 el Ayuntamiento pidió a S.M. que nombrase Regidor Perpetuo a D. Juan José Caamaño, caballero de la Orden de Malta, por haber conseguido por su influencia la habilitación del puerto. Vid. MONTERO AROSTEGUI, 202.

${ }^{27}$ MONTERO AROSTEGUI, 201.

${ }^{28}$ A.M.F.: Actas de la Junta de Arbitrios. Libro 3, 1790-93, fol. 5.

${ }^{29}$ Idem, idem, fol.7.

${ }^{30}$ Id., id., fols. 118-119.
}

"CUADERNOS DE ESTUdIOS GALLEGOS", Tomo XLII, Fascículo 107, Santiago 1995. 
Pues bien, sobre este proyecto de Caamiña ya di cuenta en un trabajo anterior $^{31}$, aunque entonces no tuve la fortuna de encontrar el album de dibujos que conformaban la propuesta del monje lego de San Martín. Por suerte, recientemente he podido localizar en el Museo Naval de Madrid tres de los cuatro dibujos que constituían el proyecto: dos de ellos referidos respectivamente a las plantas baja y principal del edificio ${ }^{32}$ (Figs. 4 y 5), y el tercero, por el contrario, alusivo al corte longitudinal y transversal de toda la fábrica proyectada ${ }^{33}$ (Fig. 6) que, por cierto, proporciona a su vez suficientes datos e información como para que, sin grandes dificultades, se pueda recomponer con una gran fiabilidad el que debió de ser diseño básico de la fachada que se abriría a la plaza de los Dolores (Fig. 7). Es decir del cuarto dibujo que es el que, precisamente, falta en el album conservado en el Museo de Madrid.

El problema, no obstante, que presentan estos planos es que, ni están fechados ni llevan tampoco firma completa de autor; sólo las siglas F.P.C. con una pequeña rúbrica $\mathrm{y}$, en el reverso, una data moderna que ha sido interpretada por los catalogadores del Archivo como 1794. No creo, sin embargo, que esto, a la luz de la documentación que se ha conservado en el Municipal de Ferrol, constituya un problema, ya que gracias a ella se puede constatar que la fecha del proyecto tiene que ser necesariamente la de 1791 y las siglas señaladas una abreviada mención de responsabilidad que sin duda hacen alusión al autor que se ha señalado: el monje benedictino (F)ray (P)lácido (C)aamiña.

El proyecto ferrolano tiene, pues, un destacado interés; y no ya por la información que nos proporciona respecto a la configuración y desarrollo que tenía el plan de las Casas Consistoriales de Ferrol, sino porque, asimismo, es el primer proyecto arquitectónicamente serio que conocemos de este autor compostelano del que sólo se conocían, a pesar de la fama de que

\footnotetext{
${ }^{31}$ VIGO TRASANCOS (1984), 255-256.

${ }^{32}$ Museo Naval de Madrid (M.N.M.): Cartografia Histórica. El Ferrol (Ciudad). Prisiones. Llevan respectivamente las signaturas $\mathrm{P} 3-\mathrm{A}-34$ y $\mathrm{P} 3-\mathrm{A}-35$. Aparecen reproducidos con sus correspondientes leyendas en MARTIN-MERAS y RIVERA, 301-302. Se fechan, no obstante, creo que injustificadamente en 1794.

${ }^{33}$ Idem, idem. LLeva la signatura P3-A-36. También aparece fechado injustificadamente en 1794. Vid. MARTIN-MERAS y RIVERA, 296.
}

"CUADERNOS DE ESTUdiOS GALLEGOS", Tomo XLII, Fascículo 107, Santiago 1995. 


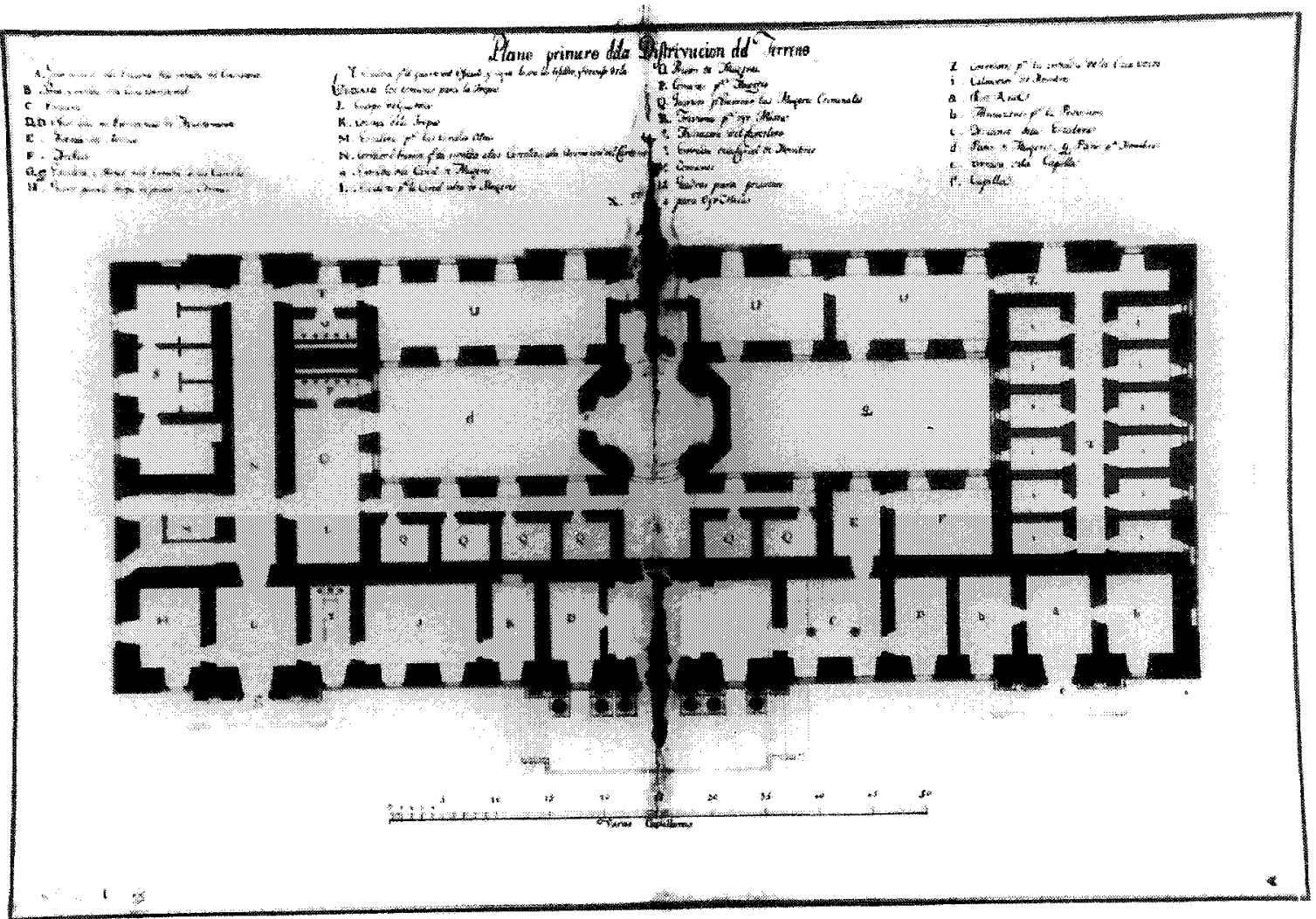

Fig. 4.- Planta baja de las Casas Consistoriales y Cárceles proyectadas en 1791 por Fray Plácido Caamiña (Museo Naval de Madrid) 


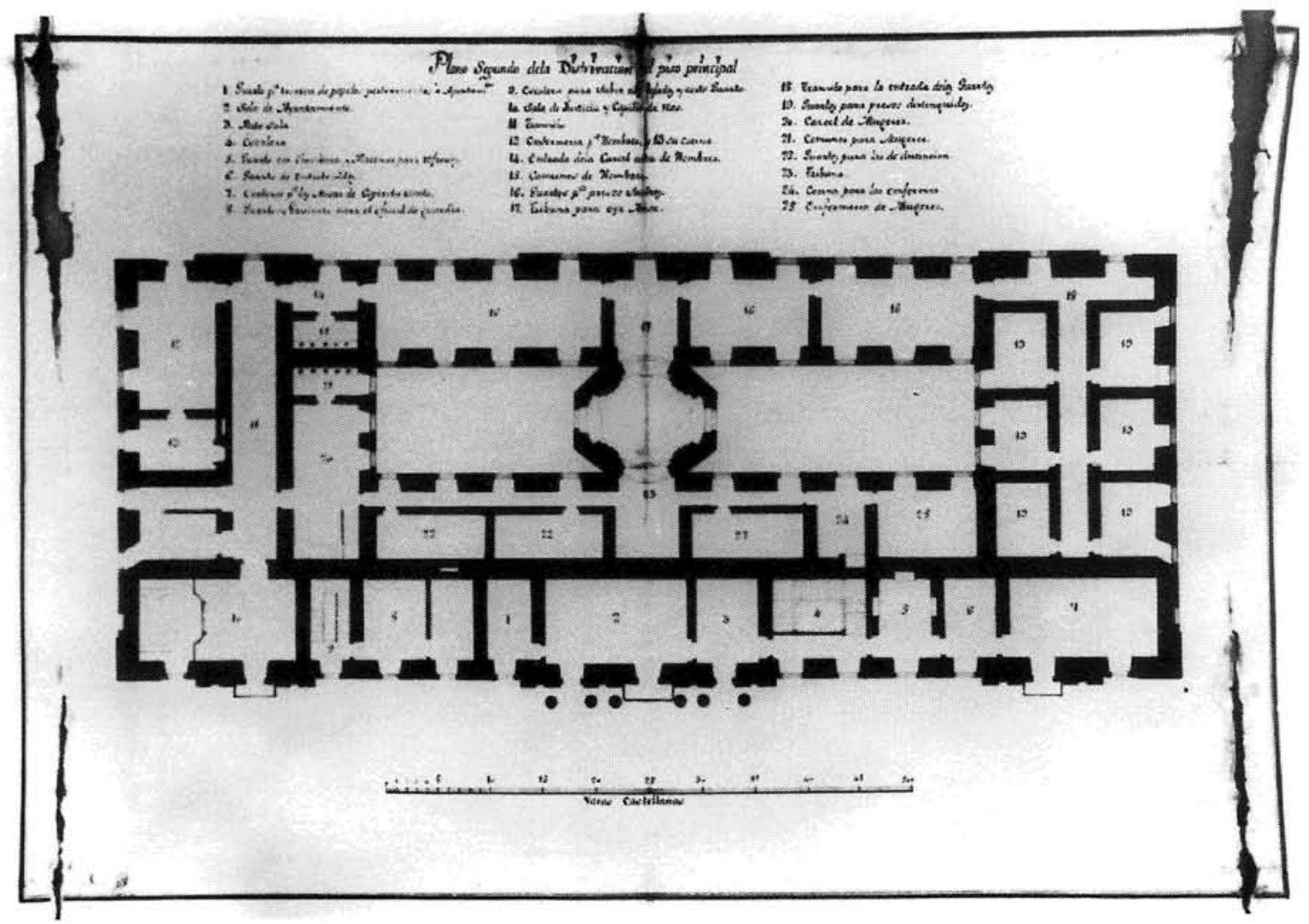

Fig. 5.- Planta noble de las Casas Consistoriales y Cárceles proyectadas en 1791 por Fray Plácido Caamiña

(Museo Naval de Madrid) 


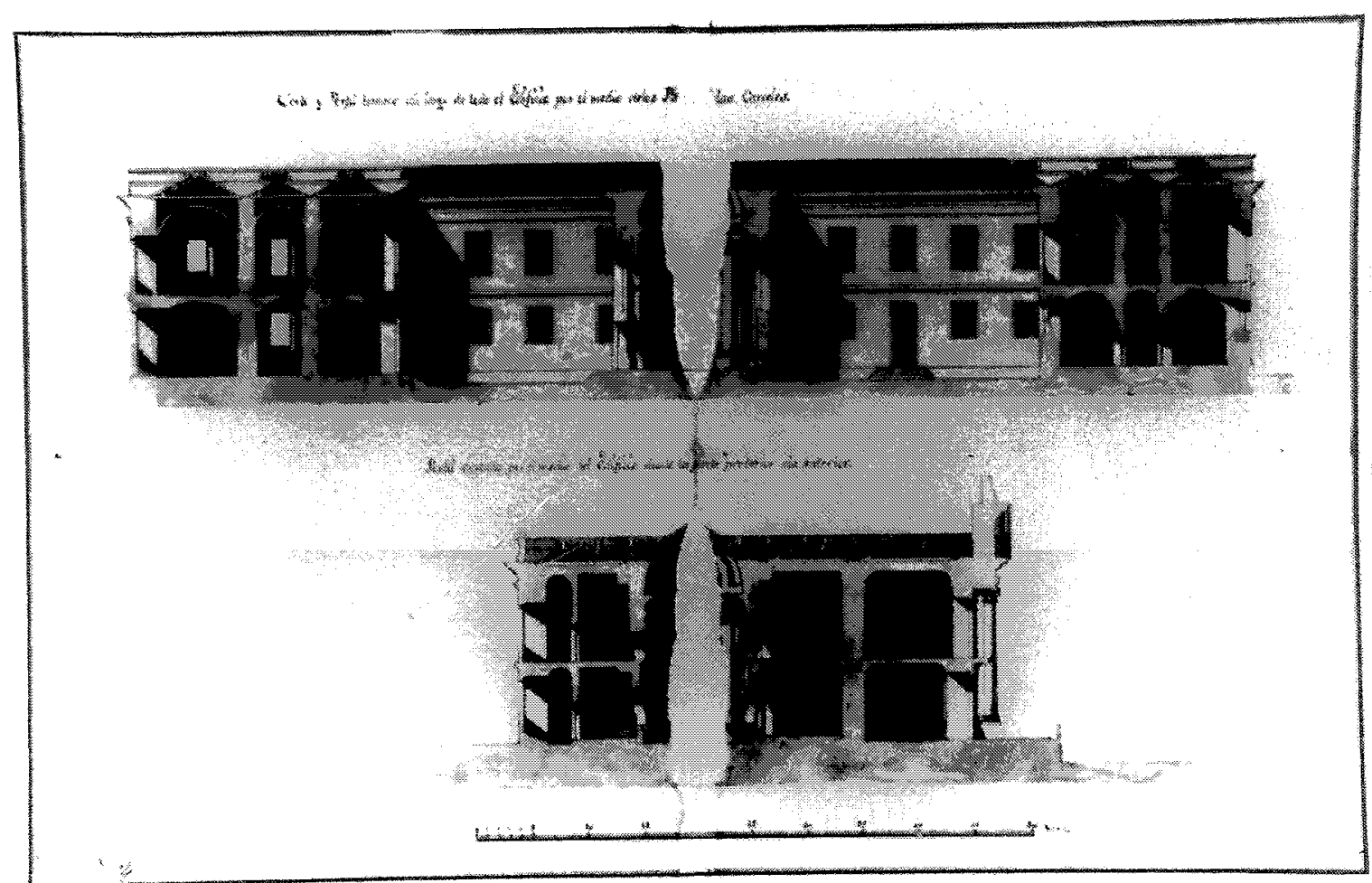

Fig. 6.- Corte longitudinal y transversal del proyecto de las Casas Consistoriales y Cárceles proyectadas en 1791 por Fray Plácido Caamiña (Museo Naval de Madrid) 


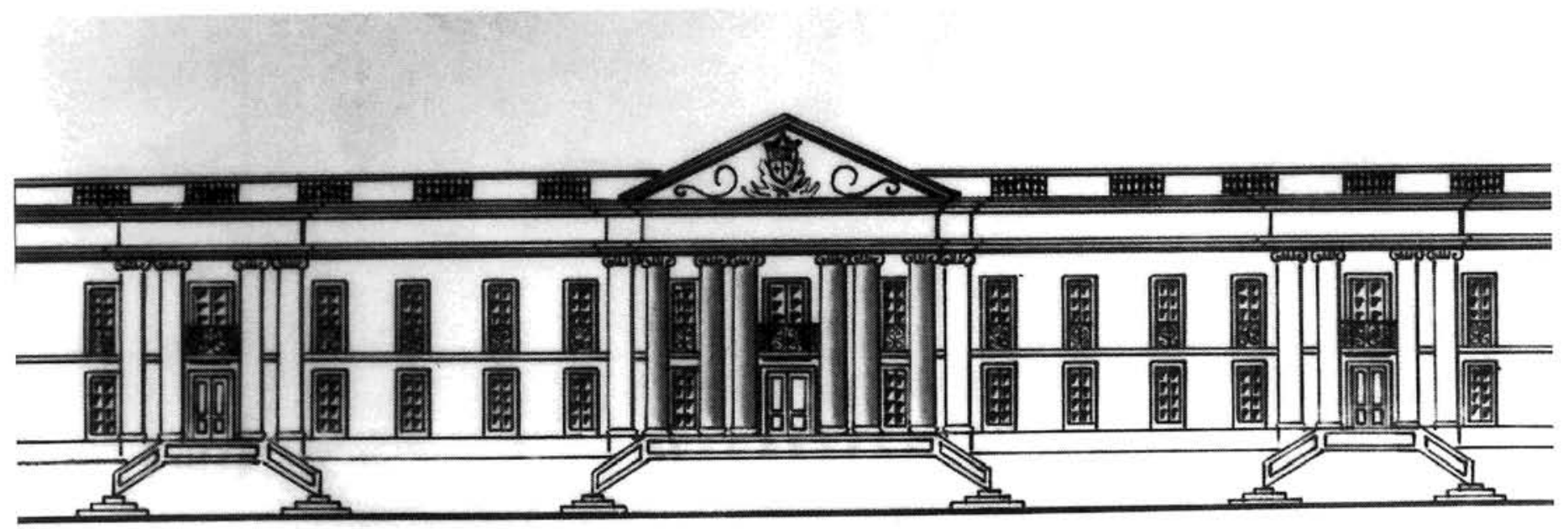

Fig. 7.- Reconstrucción conjetural de la fachada principal de las Casas Consistoriales y Cárceles proyectadas en 1791 por Fray Plácido Caamiña (dibujo de Vicente Vigo) 
gozó en su tiempo ${ }^{34}$, obras de carácter muy distinto como era el caso del Monumento de Jueves Santo que diseñó para la iglesia santiaguesa de San Martín Pinario o de ciertos retablos que también elaboró para distintas capillas que se encuentran en el interior del mismo templo ${ }^{35}$. Por consiguiente, su análisis puede resultar verdaderamente decisivo tanto para conocer la talla de Caamiña como arquitecto, como para saber cuál pudo ser su formación en el campo concreto de esta actividad en cuestión.

Respecto a su proyecto de Casas Consistoriales y Cárceles debe decirse, no obstante en primer lugar, que estaba previsto para ocupar la totalidad de la manzana norte de la plaza de los Dolores y, por tal razón, sus dimensiones tenían que ajustarse con un rigor extremado a unas medidas preexistentes que habían sido establecidas por Jorge Juan cuando procedió a elaborar el plano final de la Nueva Población en 1762. Es decir, a un paralelogramo rectangular de 100 varas de largo por 40 varas de ancho ( 83 metros de frente por 33 de profundidad aproximadamente), lo que explica que la planta del edificio proyectado por el fraile resulte extraordinariamente larga en su frente con respecto a su más comedido desarrollo en profundidad. Estaba, por lo demás, pensado para ser levantado sobre una alta plataforma a la que se ascendería por tres escalinatas dispuestas ante sus respectivas puertas. $\mathrm{Y}$ ya sobre ella se desarrollaba el esquema

${ }^{34}$ Sobre su figura, muy poco conocida, puede consultarse MURGUIA, 147 y 201; COUSELO BOUZAS, 212-214; BOUZA BREY (1944-1945), 663-672; BOUZA BREY (1945), 35-36; AR1AS, 180-182; BARREIRO FERNANDEZ, 147-188; GARCIAALCAÑIZ (1986), II, 760; SA BRAVO, 30; FERNANDEZ REY, 351-393 y CARPENTE FERNANDEZ, 395-408. Había nacido en Samos en 1746. Tomó el hábito como monje lego en San Martín en 1770. Comenzó a ejercer la profesión a partir de 1771. Falleció en 1812. Fundamentalmente se lo conoce por sus diseños para retablos, cajonerías, púlpitos y rejas; aunque al parecer también fue capaz de inventar una «máquina tormentaria» que fue muy elogiada por la Academia de San Fernando de Madrid. Vid. MURGUIA, 201 y COUSELO BOUZAS, 213. También se lo vincula con las obras finales y académicas de la Iglesia de San Francisco de Santiago trazada en estilo barroco por Simón Rodríguez; sin embargo ningún documento de los consultados hasta la fecha dan cuenta de él en este complejo religioso. Vid. FOLGAR DE LA CALLE, 127 y ss.

${ }^{35}$ Cfr. OTERO TUÑEZ (1951), 35-47; OTERO TUÑEZ (1953), 51-62; OTERO TUÑEZ (1958), 95-111; LOPEZ VAZQUEZ (1990, I , II y III), 335-336, 337-338 y 338339 y MONTERROSO MONTERO, 409-427. Son de él, al parecer, las trazas del de Santa Escolástica, de los dos colaterales de la Capilla del Socorro y el del Cristo de la Paciencia. También es probable que sea de su invención el de Santa Gertrudis. Todos ellos fueron ejecutados en las décadas de 1770 y 1780.

"CUADERNOS DE ESTUdiOS GALLEGOS", Tomo XLil, Fascículo 107, Santiago 1995. 
básico de la planta propiamente dicha compuesta por un alargado sector principal orientado en sentido de la plaza ${ }^{36}$, dos alas colaterales de mayor anchura proyectadas en forma de $\mathbf{U}$ hacia la calle posterior ${ }^{37}$ y un cuarto pabellón más estrecho que serviría de elemento de unión en la zona dispuesta hacia la espalda, todo, eso sí, organizado en torno a una patio interior alargado que al quedar presidido en su centro por un recinto semiautónomo destinado a capilla quedaba virtualmente dividido en dos partes perfectamente diferenciadas.

A juzgar por la forma y disposición de la planta, no cabe dudar que el proyecto de Caamiña tiene una gran coherencia compositiva y asimismo una conformación adecuada para el uso multifuncional a que se destinaba el edificio; hasta tal punto que así, mientras el sector delantero se preveía para acoger los vestíbulos, escribanías, Peso Real, archivo, escaleras principales y todos los salones del Concejo y de la Audiencia, el resto de las zonas de la construcción se destinaban, por el contrario, para cárceles de mujeres y hombres bien separadas entre sí y abiertas cada una respectivamente a los dos sectores del patio, quedando por lo demás toda la composición presidida en su centro por la destacada y casi autónoma capilla central que resplandecía así formalmente con su esquema circular inscrito en un perímetro de formas octógonas. Y todo esto quiere decir que, junto a unos criterios marcadamente funcionales, el plan de Caamiña también contempló planteamientos de tipo jerárquico y representativos que explican que lo más noble de la construcción (salones oficiales, escaleras, etc.) se instalase en la fachada principal, las cárceles en cambio en las partes posteriores y la capilla, finalmente, en el centro mismo del edificio a fin de recoger las luces de los dos patios desplegados en sus flancos y de servir a la vez de núcleo simbólico y vertebrador de todo el conjunto.

Del edificio, sin embargo, lo más destacado desde el punto de vista de la cualificación arquitectónica era la fachada prevista, teniendo en cuenta que su destino último era servir de ornato público a la Villa-Capital y, en definitiva, de «monumento urbano» cargado de toda una serie de connotaciones de tipo representativo.

Ya hemos dicho que, forzosamente alargada, además de estar dispuesta en un lugar que dominaba la plaza desde lo alto estaba, a su vez, montada sobre una extensa plataforma a la que se ascendía por tres escalinatas que

\footnotetext{
${ }^{36}$ Entre edificio y plaza, sin embargo, mediaría la llamada Calle María.

${ }^{37}$ La Ilamada Calle del Sol.
} 
al llegar a la altura de la planta baja formaban una especie de pequeñas terrazas concebidas a manera de balcones-mirador. Sobre ella, por tanto, se desplegaba el gran frente distribuido en dos cuerpos, ritmado por la seriada disposición de sus vanos y presidido todo él por tres estructuras monumentales de pilastras jónicas pareadas las de los extremos dispuestas a ambos lados de las puertas secundarias y de seis columnas del mismo orden la de la puerta principal que así confería al frente un tono solemne y templario dominada como estaba por un amplio frontón de forma triangular. Por lo demás, todo el edificio quedaría recorrido en su parte alta por una elegante balaustrada, por muros secos y adustos simplemente horadados de ventanas en sus cierres secundarios y patios y, con respecto a la capilla interior y central, sólo señalar que era axigua, centralizada y de planta circular inscrita en un octógono, si bien disponía para su mínima cualificación de una sobria articulación interior de cuatro pilastras jónicas, una cubierta cupulada y, como remate, posiblemente de una pequeña linterna que posibilitaba la iluminación cenital de todo su espacio interno. Esto, pues, constituía la forma básica de la capilla de la cárcel. Pero hay que decir que, junto a su espacio principal, el recinto religioso también disponía de un pequeño espacio posterior pensado para sacristía y de pequeñas tribunas altas destinadas para que las autoridades pudieran oir misa desde otro nivel diferente al de los presos.

Tal planteamiento, en todo caso, si llama nuestra atención es, entre otras cosas, porque parece querer diferenciarse con rotundidad manifiesta del proyecto que, con anterioridad y para el mismo fin, había diseñado Sánchez Aguilera en 1786. En éste dominaban, si son ciertos los datos aportados por Montero Aróstegui, criterios porticados que buscaban vincular el edificio con la calle y, en definitiva, con la plaza que habría de desplegarse a sus pies; por el contrario, en la idea de Caamiña imperan soluciones claramente retóricas y diferenciadoras que optan por resaltar el edificio no sólo con formas contundentes, sino con elementos como las escalinatas y la plataforma que aspiran a separarlo del entorno y a destacar su masa con un claro efecto escénico y ciertamente abrumador.

Ahora bien, hemos dicho que el análisis del edificio, tanto en lo que se refiere a la planta, a la fachada como a la propia capilla, nos informa también con suficiente claridad sobre cuál pudo ser la formación arquitectónica de su autor. De él poco más sabemos que, a pesar del tiempo finisecular en que vivió, no se educó en las aulas de la Academia, sino en las propias celdas del monasterio de San Martín de las que habían salido eminentes arquitectos de clara filiación vernácula y barroca. Sin embargo,

"CUAdeRnOS DE ESTUdIOS GALLEGOS", Tomo XL11, Fascículo 107, Santiago 1995 
esto no explica con claridad el lenguaje clasicista filoilustrado que Caamiña manifiesta en el proyecto de Ferrol, lo que quiere decir que, al margen de que pudiera conocerlo a través de ciertos tratados de arquitectura que entonces estaban en uso (Alberti, Serlio, Viñola, Palladio,Briseux, Daviler, Blondel, etc.) lo más probable es que lo aprendiese de un modo directo en las distintas obras de tono académico que, a partir de la segunda mitad del siglo, se habían erigido en la ciudad de Santiago (Fachada de Azabachería de la Catedral, Capilla de la Comunión, Seminario de Confesores, Universidad, Capilla de Animas, etc.) o en su entorno más inmediato (Archivo del Reino de Galicia en Betanzos, Ayuntamiento de la misma ciudad o, ya en La Coruña, en edificios como las Casas de Paredes, Aduana, Consulado, etc. ${ }^{38}$. La planta, de hecho, aunque distinta en muchos aspectos, no deja de estar sin relación con ciertos planteamientos que se aprecian en el edificio del Seminario de Confesores de Santiago proyectado por Carlos Lemaur en 1767 y que, no lo olvidemos, también acogía las Casas Consistoriales y las Cárceles de la Ciudad ${ }^{39}$ (Fig. 8). Se ve la relación, sobre todo, en la idea de plantear un esquema de brazos en $\mathbf{U}$ orientados hacia el fondo y ambos con sendos pasillos centrales dispuestos a manera de columna vertebral en su interior. El mismo patio alargado y la propia estructura puente que cruza el edificio ferrolano por las espaldas uniendo los dos cuerpos proyectados también parecen tener una cierta relación con el Seminario. Y la misma capilla central no deja de evocar, siquiera en algo, el papel rector, la forma octógona y aún el ligero avance que, sobre el patio, tiene la estructura que encierra las escaleras principales en el noble edificio compostelano. Aquí, no obstante, junto al ejemplo santiagués, tal vez haya que referirse a otras fuentes de tipo libresco, ya que el papel semiexento, vertebrador y separador que la capilla tiene en el dibujo de Ferrol parece relacionarse con ciertas planimetrías arquitectónicas del mundo antiguo seguramente tomadas de Serlio $^{40}$ (Tepidarium de las Termas de Diocleciano en Roma (Fig. 9)) y acaso también con ciertas prácticas y modos de hacer que tanto se ven en edificios dieciochescos del barroco italiano (Carceri Senatorie de Turín ${ }^{4 !}$ según el proyecto de Benedetto Alfieri de 1740), como en obras más mo-

\footnotetext{
${ }^{38}$ Vid. VIGO TRASANCOS (1992, II).

${ }^{39}$ Sobre este magnífico edificio compostelano puede consultarse ORTEGA ROMERO (1966) y especialmente VIGO TRASANCOS (1992,1).

${ }^{40}$ SERL1O, Terzo Libro. Delle Antichita, p. 95 v

${ }^{4 !}$ Cfr. ilustración en BELLINI, 132.
}

"CUADERNOS DE ESTUdIOS GALLEGOS", Tomo XLII, Fascículo 107, Santiago 1995. 


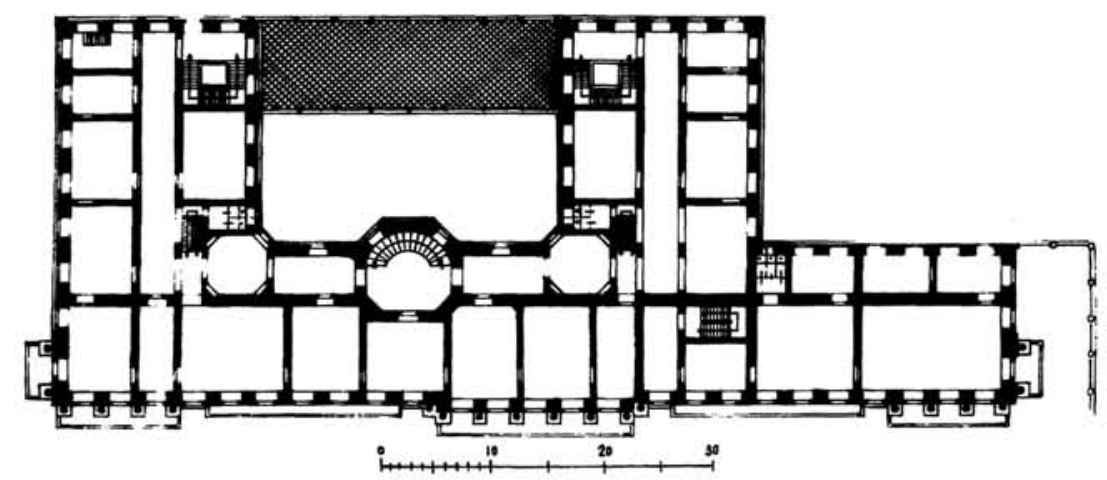

Fig. 8.- Planta noble del Seminario de Confesores y Ayuntamiento de la Ciudad de Santiago. Carlos Lemaur. 1767 (según O. Schubert).

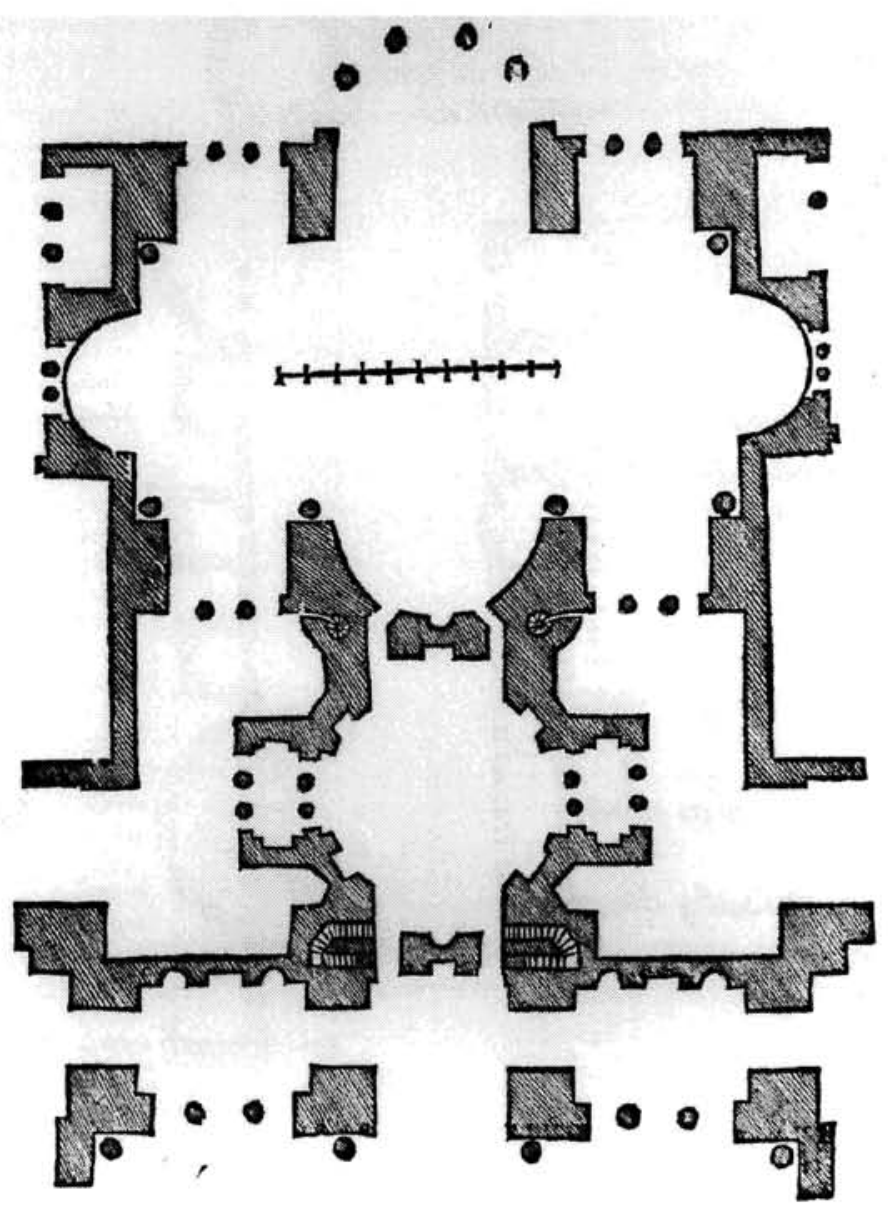

Fig. 9.- Sector parcial de las Termas de Diocleciano en Roma con la estructura del Tepidarium rotondo en el centro (según Serlio). 
dernas del estilo de la que Schinkel, en 1835, planteó para la Staatsbibliothek de la ciudad de Berlín ${ }^{42}$ (Fig. 10), lo que explica el influjo de los dos medios en la formación arquitectónica del benedictino.

De todas formas, las referencias a Serlio y al ambiente arquitectónico local no sólo se aprecian en la organización de la planta del proyecto ferrolano, sino incluso más aún en la solución conferida a la plataforma, a las escalinatas y a la misma fachada presidida como está con su frontis templario y hexástilo de columnas jónicas y remate de frontón. Algo evoca, de hecho, la solución contemplada por Serlio para un gran palacio campestre tal y como se ve en el dibujo reproducido en la página 41 del Libro VII de su tratado de arquitectura (Fig. 11) y mucho más, si cabe, los planteamientos dados por Domingo Lois a ciertos proyectos elaborados antes de su llegada a Compostela en $1765^{43}$ y que, por qué no, pudo traer con él y ser conocidos por Caamiña (Figs. 12 y 13). Con todo, el edificio santiagués que habla más a las claras respecto al influjo que ciertamente causó sobre Caamiña y su proyecto de Consistorio para Ferrol es indudablemente el de la propia Universidad según la planteó en distintos momentos el arquitecto local Miguel Ferro Caaveiro ${ }^{44}$. Y no hay más que comparar el diseño de Ferrol con el proyecto compostelano(Fig. 14) y su resultado final(Figs. 15 y 16) para confirmar la veracidad de nuestro aserto.

Queda, por último, hacer referencia a la estructura y espacio que Caamiña contempló para la capilla central de la Cárcel ferrolana. Ya hemos señalado que en su planta trae, en parte, el recuerdo de la caja de escaleras del Seminario santiagués proyectada por Lemaur que, por cierto, culmina en

\footnotetext{
${ }^{42}$ Vid. PEVSNER, 125.

${ }^{43}$ Uno de ellos, sin duda el más majestuoso, se trata de un proyecto de "Casa de Campo de un Grande» que elaboró en 1758 y que le valió ser pensionado a Roma por la Academia de San Fernando de Madrid. Sobre la figura de Lois, hoy bastante bien conocida, pueden consultarse como obras más recientes CERVERA VERA y VIGO TRASANCOS (1989, I y II). Para su actividad en Andalucía y concretamente en el antiguo Reino de Granada vid. GUILLEN MARCOS (1989) y (1990).

${ }^{44}$ Sobre este arquitecto compostelano tan decisivo en el último tercio del siglo XVIII puede verse ORTEGA ROMERO (1970) y (1974). Fue, tal como se ha dicho, el principal responsable del proyecto para la Universidad de Santiago; pero debe recordarse que antes que él, en concreto el 18 de Septiembre de 1773, Caamiña había sido nombrado por el Consejo de Castilla maestro de las obras del nuevo edificio, aunque poco duró en el cargo ya que, a partir de 1774, lo sucede Miguel Ferro Caaveiro. Vid. GARCIA-ALCAÑIZ (1989), 92 .
}

"CUADERNOS DE ESTUDIOS GALLEGOS", Tomo XLII, Fascículo 107, Santiago 1995. 


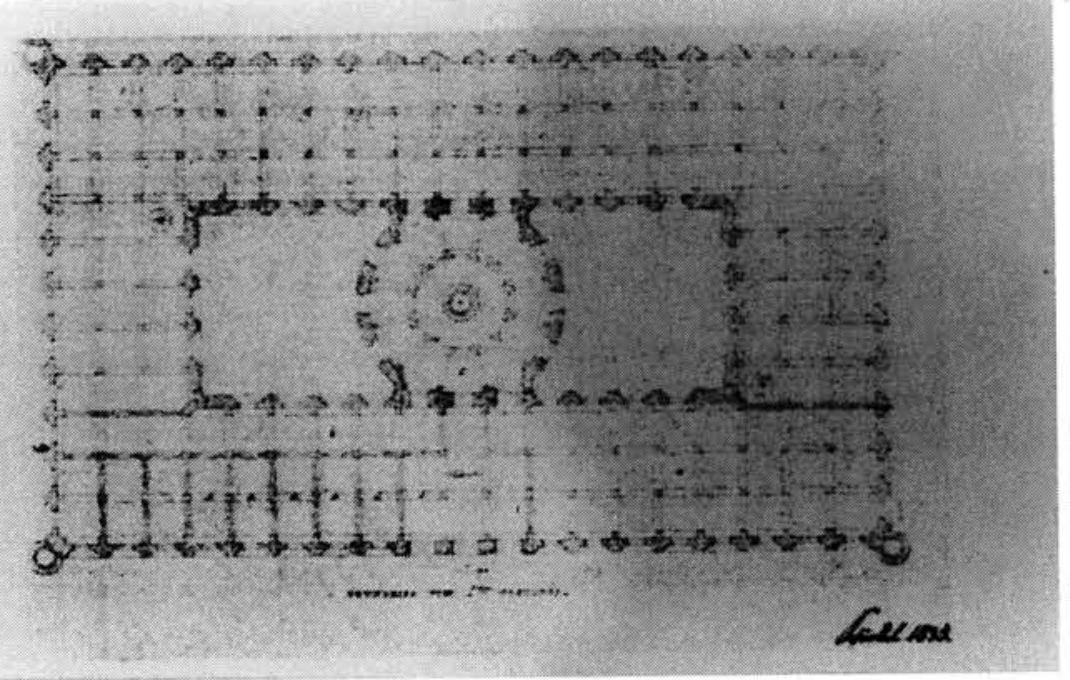

Fig.10.- Proyecto de Schinkel para la Biblioteca Nacional de Berlín. 1835.

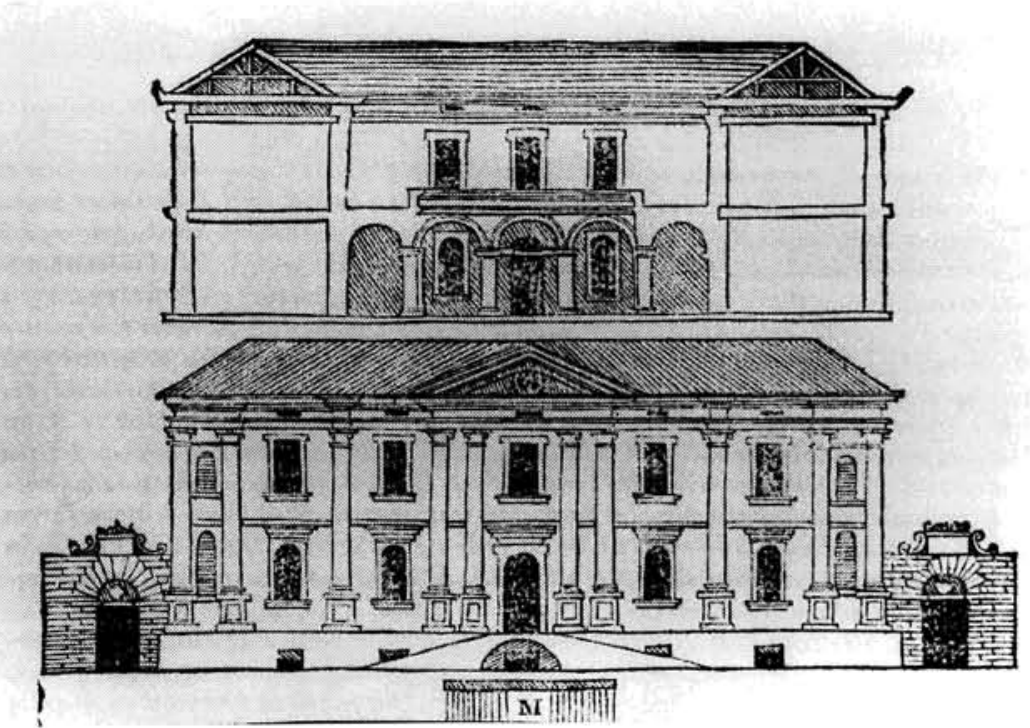

Fig.11.- Propuesta de una Casa de Campo para un Gran Señor (según Serlio). 


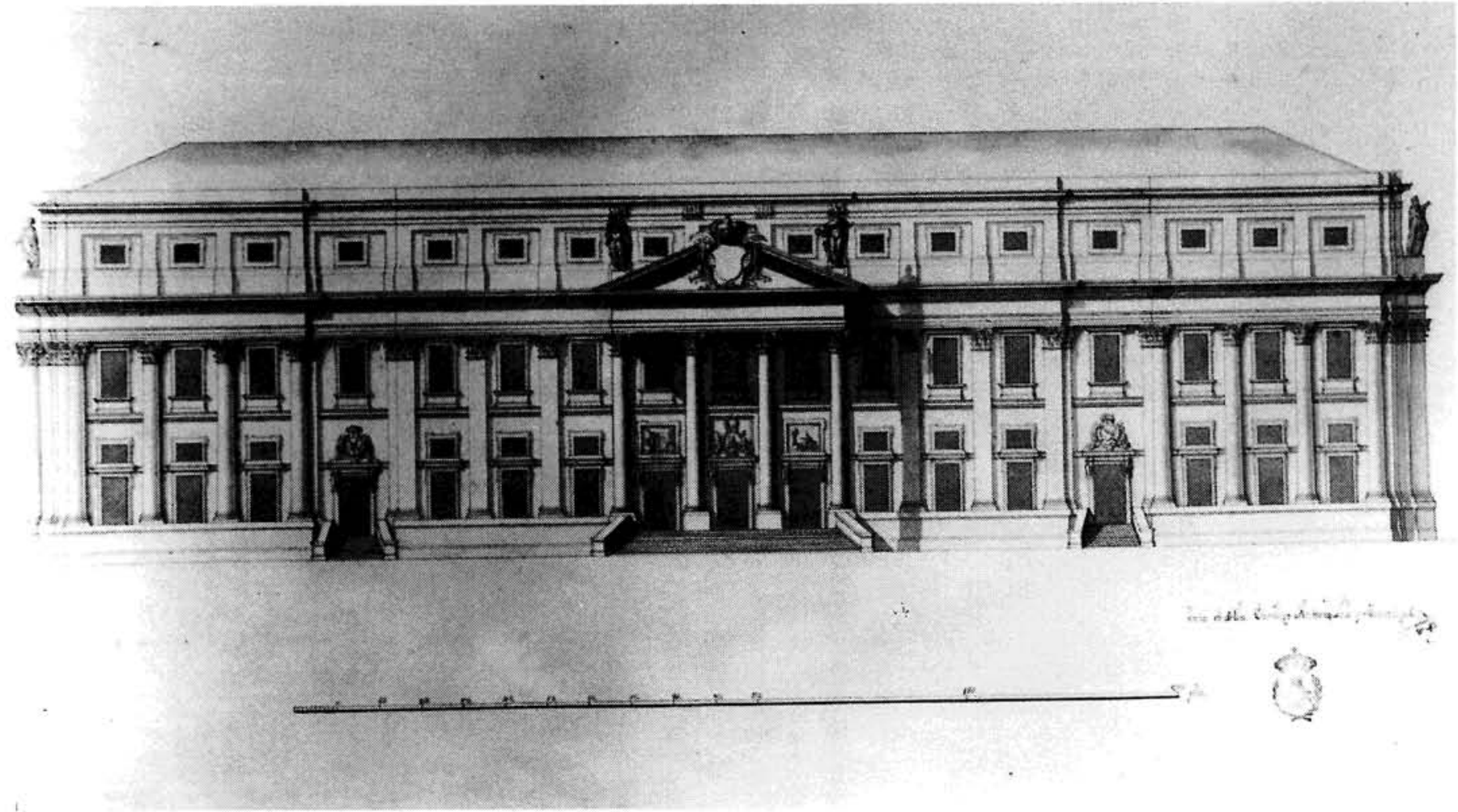

Fig.12.- Propuesta de Casa de Campo para un Grande. 1758. Domingo Lois Monteagudo. 


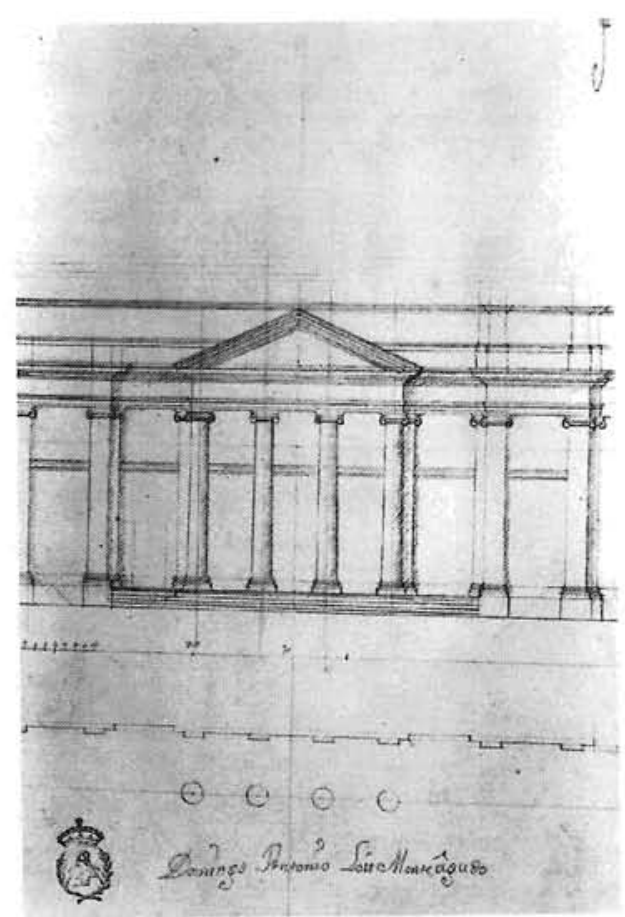

Fig.13.- Dibujo para una fachada de un edificio noble. Domingo Lois Monteagudo.
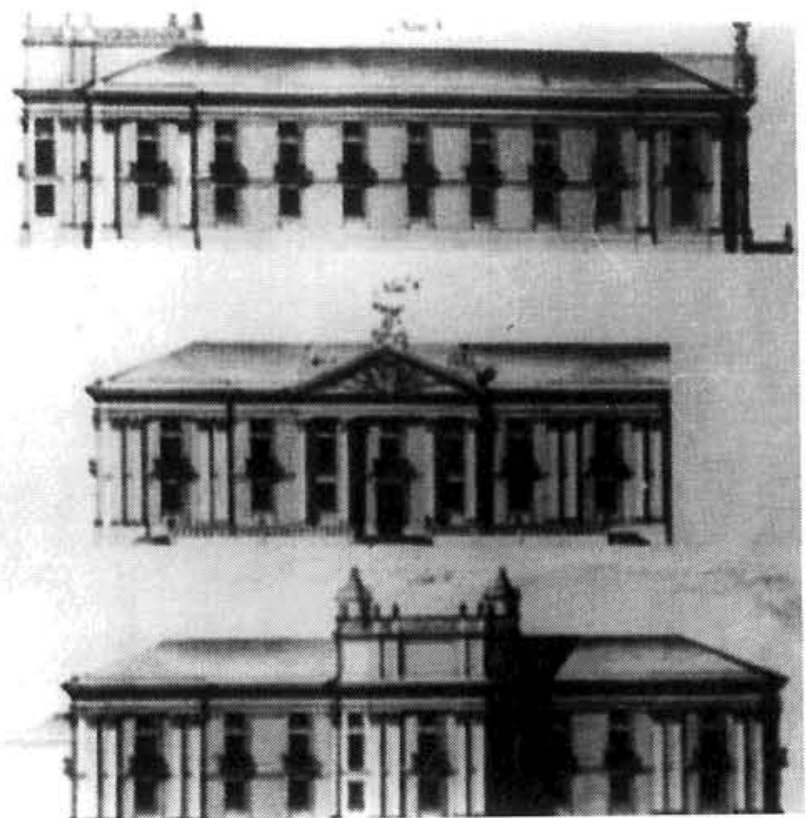

Fig.14.- Proyecto de Miguel Ferro Caaveiro para la Universidad de Santiago. 


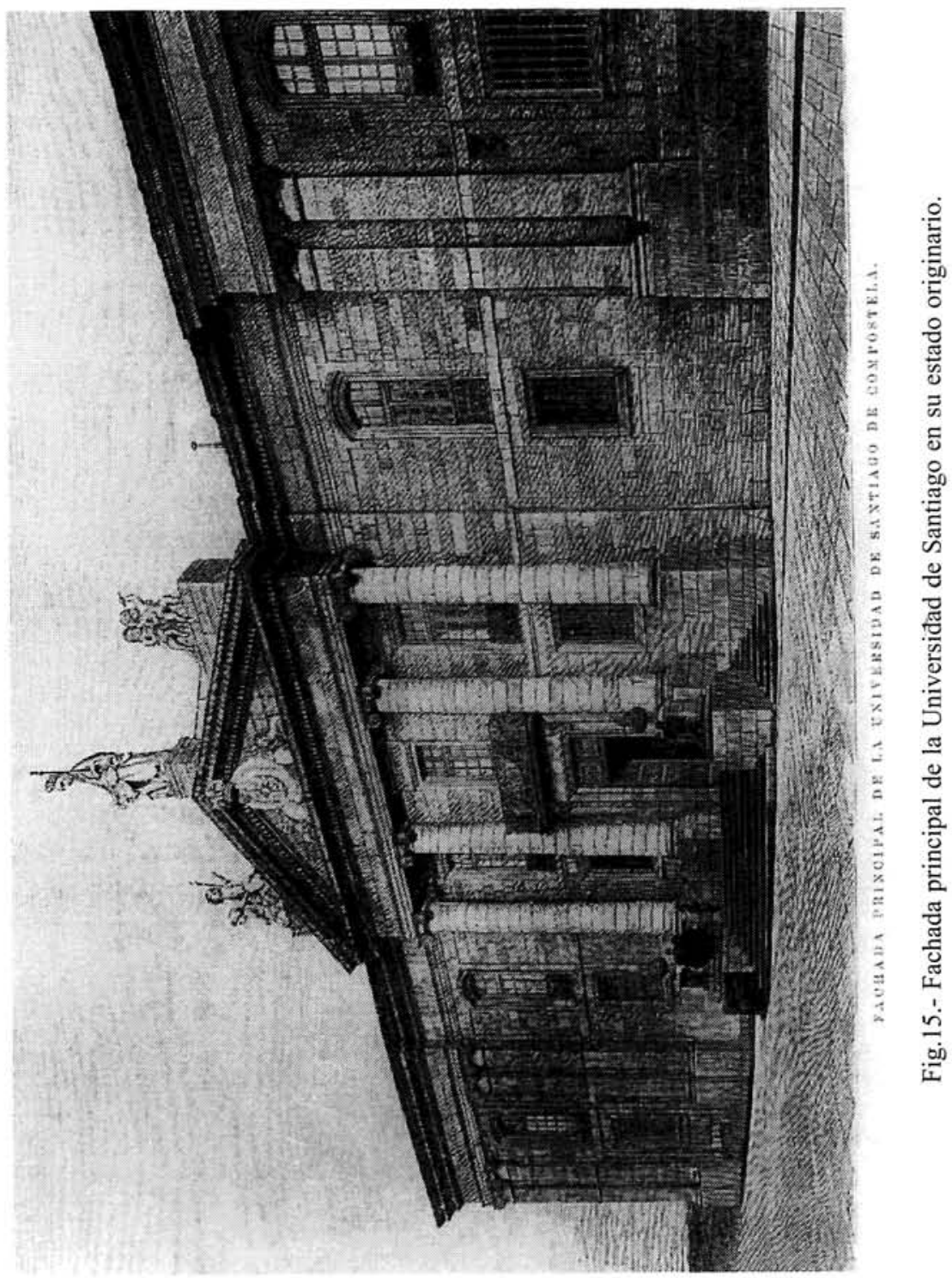




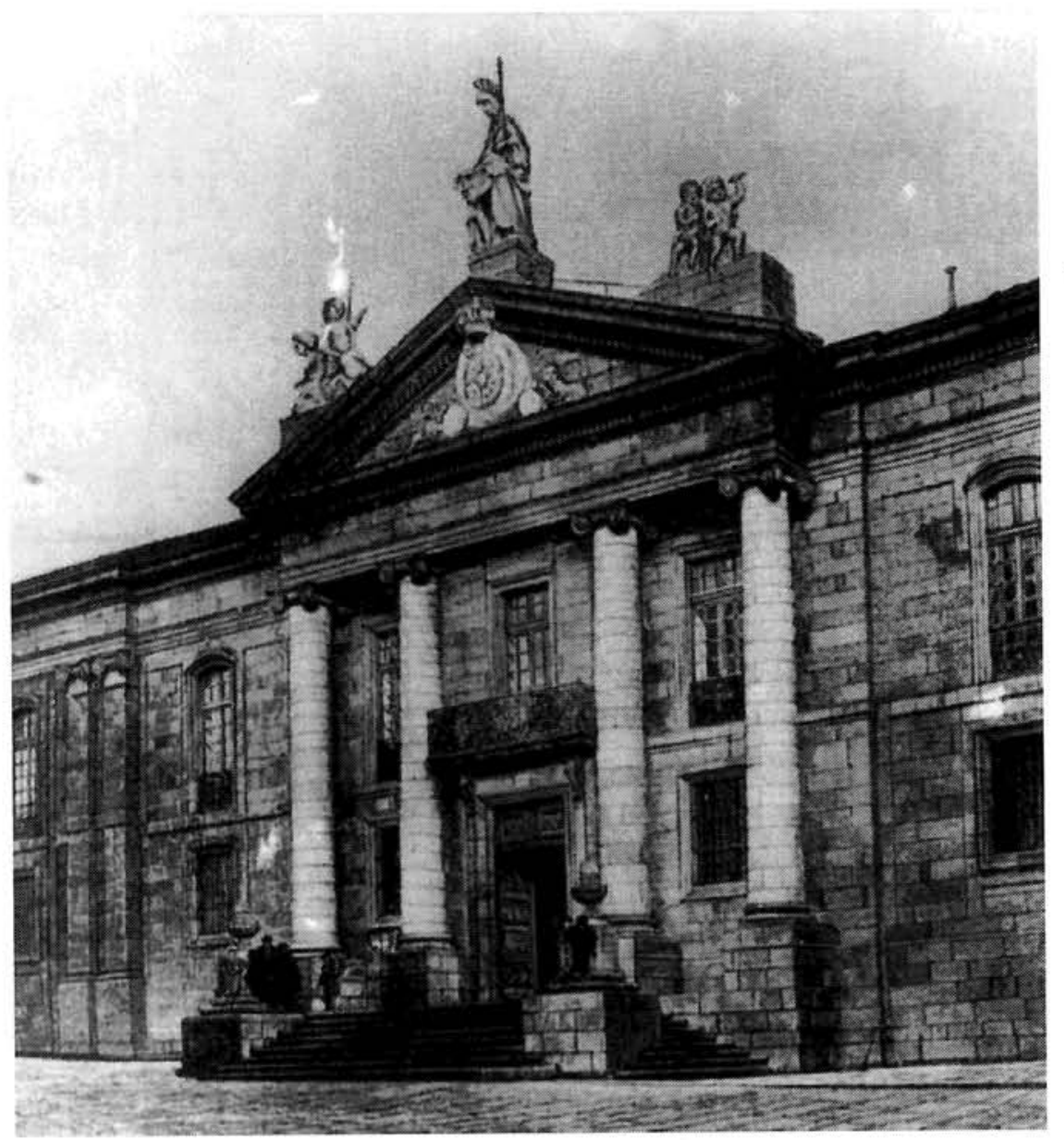

Fig.16.- Frontis templario de la Universidad de Santiago en su estado original. 
su parte alta, la que queda justamente debajo del emergente cimborrio que se ve desde el exterior, en un pequeño oratorio octogonal articulado con pilastras jónicas. Esta estructura, pues, pudo guiar someramente el planteamiento del benedictino. Aún así, pienso que no debe ser descartado el ejemplo de la Capilla de la Comunión de la Catedral de Santiago ${ }^{45}$, obra de Lois, aunque sea ciertamente más compleja, espaciosa y columnaria su organización interna.

\section{DE CONSISTORIO A CARCEL. EL PROYECTO FINAL DEL INGENIERO DE MARINA JOSE LOPEZ LLANOS (1791)}

Fue una lástima ciertamente que ni el proyecto de Sánchez Aguilera ni el de Caamiña se convirtiesen en realidad. Con todo, aunque se descartasen por motivos diferentes, tal vez por la marcha del promotor en el primer caso y por problemas económicos en el segundo, la Ciudad siguió empeñada en erigir un edificio noble y público en el espacio que para él se había reservado en la plaza de los Dolores. En esta tercera ocasión, a punto estuvo de conseguirlo; pero hay que decir que, esta vez, el proyecto que el Rey manda ejecutar el 9 de Noviembre de 1791 ni había sido remitido por la Corporación sino por las Autoridades de Marina ${ }^{46}$ que lo habían encargado al ingeniero José López Llanos, ni tampoco contemplaba la construcción de un amplio edificio destinado a Consistorio, sino otro mucho más modesto que se pensaba exclusivamente para alojar las Cárceles y los Juzgados $^{47}$ (Fig. 17). Al final el elevado coste que conllevaban las obras de los desmontes que había que realizar en el lugar elegido motivó que el

\footnotetext{
${ }^{45}$ Respecto a esta capilla catedralicia Cfr. VIGO TRASANCOS $(1989$, I). Fue trazada por Lois entre 1766 y 1767. Sus obras se iniciaron en 1768.

${ }^{46}$ Era entonces Capitán General del Departamento D. Antonio de Arcc. A.M.F.: Actas de la Junta de Arbitrios. Libro 3, 1790-93, fol. 137.

${ }^{47}$ MONTERO AROSTEGUI, 281. Los planos del proyecto de López LLanos que se conservan en el Museo Naval de Madrid fueron publicados hacc pocos años por SORALUCE BLOND, 132. Fueron aprobados por el Rey el 29 de Octubre de 1791. Dada sus escasas dimensiones sobra indicar que, en este caso, el nuevo edificio sólo ocuparía el sector central de la Plaza de los Dolores quedando sus colaterales libres para disponer dos zonas con vegetación. Vid. al respecto el plano $n^{\circ} 788$ que aparece reproducido $\mathrm{cn}$ MARTIN-MERAS y RIVERA, 303. LLeva la signatura P3-A-48 y la siguiente leycnda: «Plano del desmonte de la plaza de los Dolores de la Villa de Ferrol».
} 


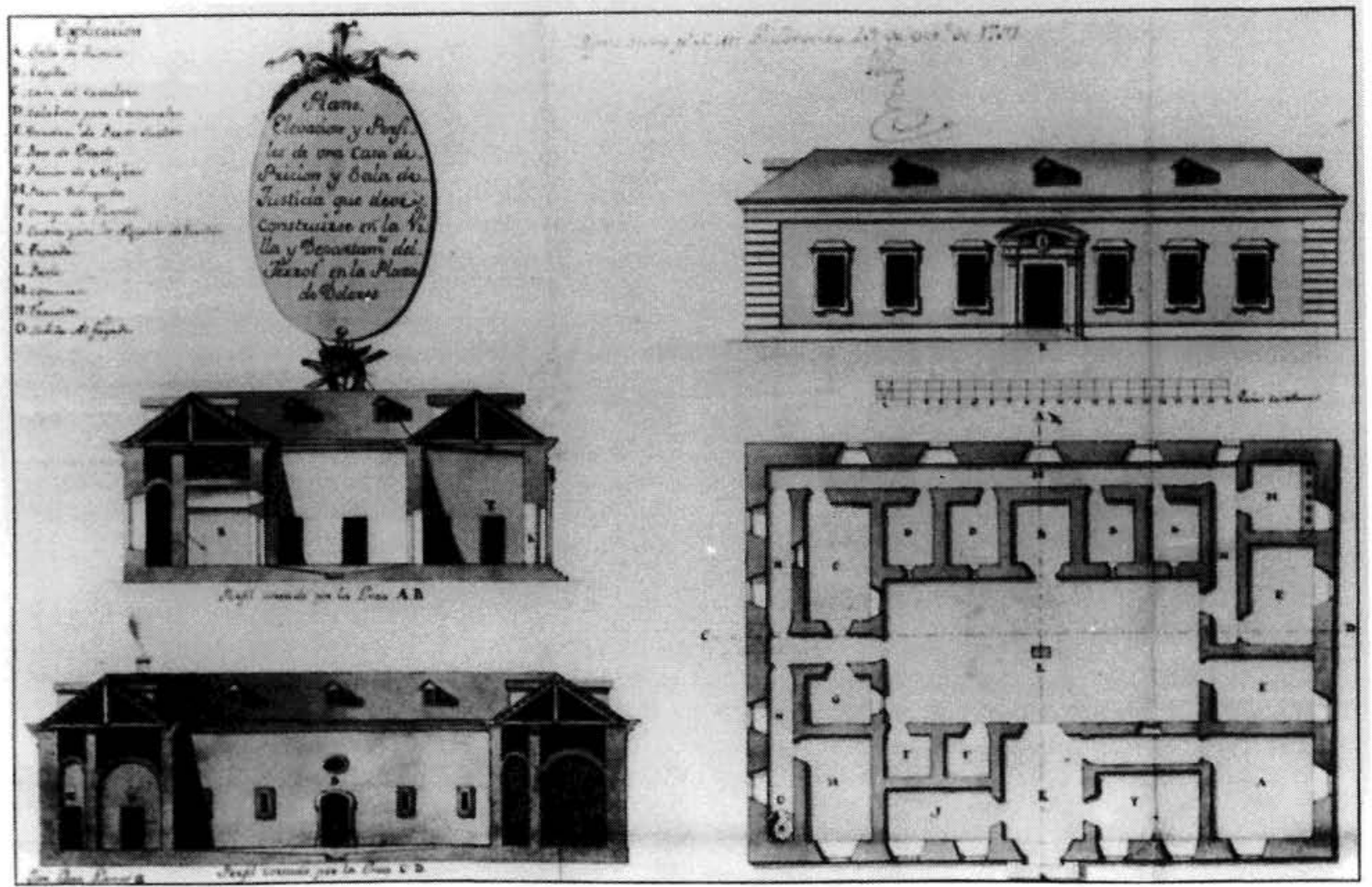

Fig.17.- Proyecto de José López LLanos para las Cárceles de Ferrol. 1791 (Museo Naval de Madrid). 
proyecto de LLanos para las Cárceles primero se suspendiese por Orden Real del 20 de Junio de $1792^{48}$, y luego, el 12 de Octubre de 1793, que se trasladase a otro lugar; en concreto a «la medianía del Nuevo Ferrol y Esteiro, tomando 22 varas que para nada hacen falta del corralón destinado a la custodia de astillas ${ }^{49}$ que es, en efecto, el emplazamiento que ocupa el edificio en la actualidad. Se inició, pues, en Marzo de $1794^{50}$, si bien tardó en concluirse hasta $1802^{51}$. Su coste final, por último, supuso la inversión de una cifra más alta que la que inicialmente se había estimado, ya que el proyecto de LLanos que contemplaba una edificación modesta de un sólo cuerpo, al final se levantó con dos (Fig. 18), lo que ciertamente redundó en beneficio de la fábrica que así adquirió una mayor nobleza y dignidad arquitectónicas y una presencia más cualificada en el contexto urbano $^{52}$.

Hoy el edificio de la Cárcel proyectado por Llanos todavía permanece en pie en su emplazamiento originario; pero hay que decir que, como resultado de su nueva adaptación para asiento del Gobierno Militar de la Plaza, ya en nuestra época, su altura se multiplicó hasta las cuatro plantas, procediéndose asimismo a engalanar con pautas más suntuosas, aunque clasicistas, la planta noble que ya la fábrica poseía (Fig. 19).

\footnotetext{
${ }^{48}$ MONTERO AROSTEGUI, 281.

${ }^{49}$ A.M.F.: Reales Ordenes pertenecientes a la ciudad de Ferrol, fol 248.

${ }^{50}$ Idem: Actas de la Junta de Arbitrios. Libro 4, 1794-96, fol. 38.

${ }^{51}$ MONTERO AROSTEGUI, 281. No obstante, la inscripción que durante años presidió el edificio señalaba que «Reinando en las Españas las M.M. de los Sres. D. Carlos IV y Doña Maria Luisa de Borbón, se hizo este edificio puiblico, destinado a cárcel de villa, del producto del arbitrio impuesto sobre el vino, que fue establecido para tan piadoso fin. Los protectores de esta obra fueron por Real orden el Excelentisimo Sr. D. Félix de Texada, capitán general del Departamento, y el Sr. D. Domingo Hernani, intendente de Marina en él, presidente de la junta de dicho arbitrio y sustituto del señor general el Sr. Pedro de Obregón, jefe de escuadra de la Real Armada, y el que la proyectó y dirigió por orden de S.M., el capitán de fragata e ingeniero en segundo D. José López Llanos, que la concluyó en Diciembre de $1801 \%$.

${ }^{52}$ Su coste se estimó inicialmente en 261.860 reales pero el resultado final exigió una cifra mucho más alta. Nada menos que 853.481 reales. Vid. MONTERO AROSTEGUI, 281 .
}

"CUADERNOS DE ESTUDIOS GALLEGOS", Tomo XLII, Fascículo 107, Santiago 1995. 


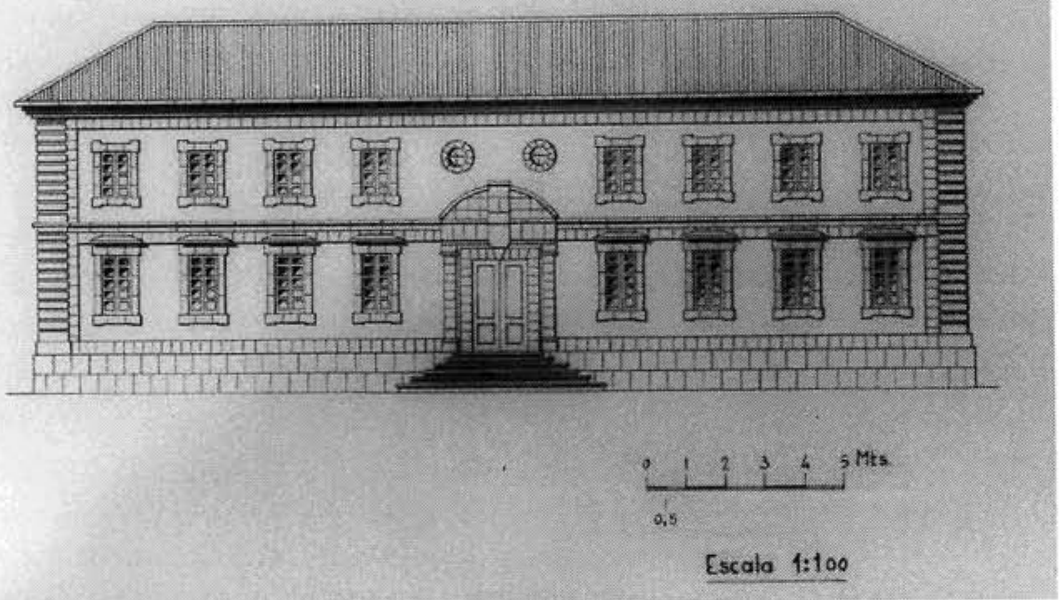

Fig.18.- Cárcel Pública de Ferrol tal como finalmente se construyó. José López LLanos. 1794-1802 (dibujo de Vicente Vigo).

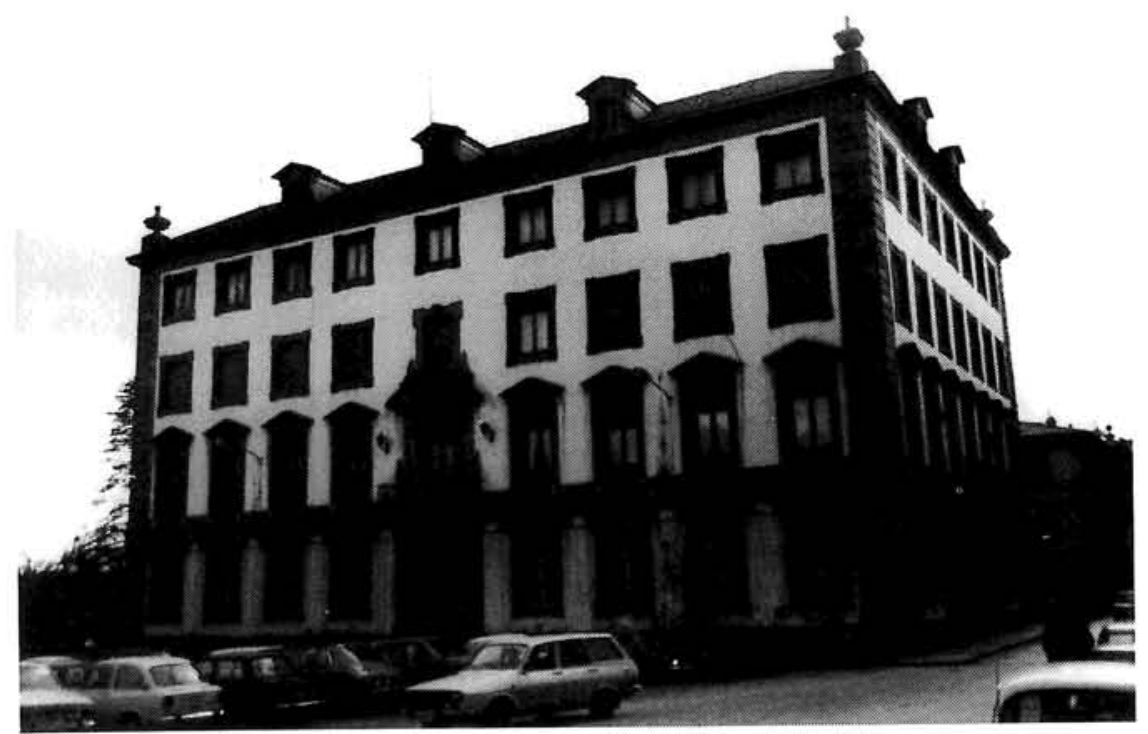

Fig.19.- Estado actual del edificio de la Cárcel tras su remodelación para servir como Gobierno Militar. 


\section{LAS SEDES SUCESIVAS DEL CONCEJO FERROLANO}

Lo dicho hasta aquí, cuando menos, viene a confirmar que las aspiraciones del Concejo ferrolano por tener unas Consistoriales nobles y bien instaladas en un espacio representativo de la Nueva Población nunca llegaron a verse cumplidas. Las salas municipales vivieron, pues, mal alojadas en una Torre y en un vetusto caserón del Viejo Ferrol hasta $1788^{53}$ en que, de un modo provisional, fueron trasladas al piso alto de la recién construida Escuela de Gramática o Cátedra de Latinidad $^{54}$ (Fig. 20) que, por cierto, había sido proyectada por el ingeniero Sánchez de Aguilera en tiempos del Alcalde Alvarez Caballero ${ }^{55}$. Allí permanecieron hasta 1802 en que, de nuevo de una manera transitoria, se instalaron en el piso noble de la Cárcel Nueva ${ }^{56}$. Pero no con ello las dependencias municipales conocerían su ubicación definitiva, ya que, finalmente, volvieron a alojarse en la Escuela de Gramática en $1847^{57}$ y hasta el comienzo de la década de 1950 en que, por último, pasaron a ocupar el actual edificio del Ayuntamiento emplazado en la Plaza de Armas ${ }^{58}$. Esta vez sí conseguía el Concejo levantar fábrica nueva en el mismo corazón del Nuevo Ferrol y presidiendo un espacio público; lástima que tal decisión conllevase la desfiguración de un precioso ámbito decimonónico que tenía personalidad propia y la usurpación de suelo ciudadano, ya que el edificio nuevo ocupa parte importante de la mencionada plaza y no uno de sus cierres perimetrales como inicialmente se había previsto en los planes que aquí se han mencionado ${ }^{59}$.

${ }^{53}$ MONTERO AROSTEGUI, 276-278. La Torre se había construido en 1613 en las inmediaciones de la llamada Puerta del Castro abierta en las murallas que circundaban el Ferrol Viejo. Allí estuvo colocado el antiguo reloj público. La Torre fue demolida en 1826.

${ }^{54}$ BAAMONDE Y ORTEGA, 62.

${ }^{55}$ Concretamente en 1786, aunque nunca llegó a levantarse con la amplitud que el proyecto preveía. Más información en MONTERO AROSTEGUI, 279-280 y VIGO TRASANCOS (1984), 256-258.

${ }^{56}$ BAAMONDE Y ORTEGA, 62.

${ }^{57}$ BAAMONDE Y ORTEGA, 62. De hecho, tanto MADOZ, 66 como MONTERO AROSTEGUI, 279 denominan al edificio Casa Consistorial en sus respectivas obras de 1850 y 1858.

${ }^{58}$ Fue inaugurado en 1953 según proyecto del arquitecto Nemesio López Rodríguez. Vid. CENDAN PAZOS, 29.

${ }^{59}$ Evidentemente hubiera sido más lógico emplazarlo en la Plaza de España que era entonces de nueva creación y por descontado mucho más espaciosa.

"CUADERNOS DE ESTUDIOS GALLEGOS", Tomo XLII, Fascículo 107, Santiago 1995. 


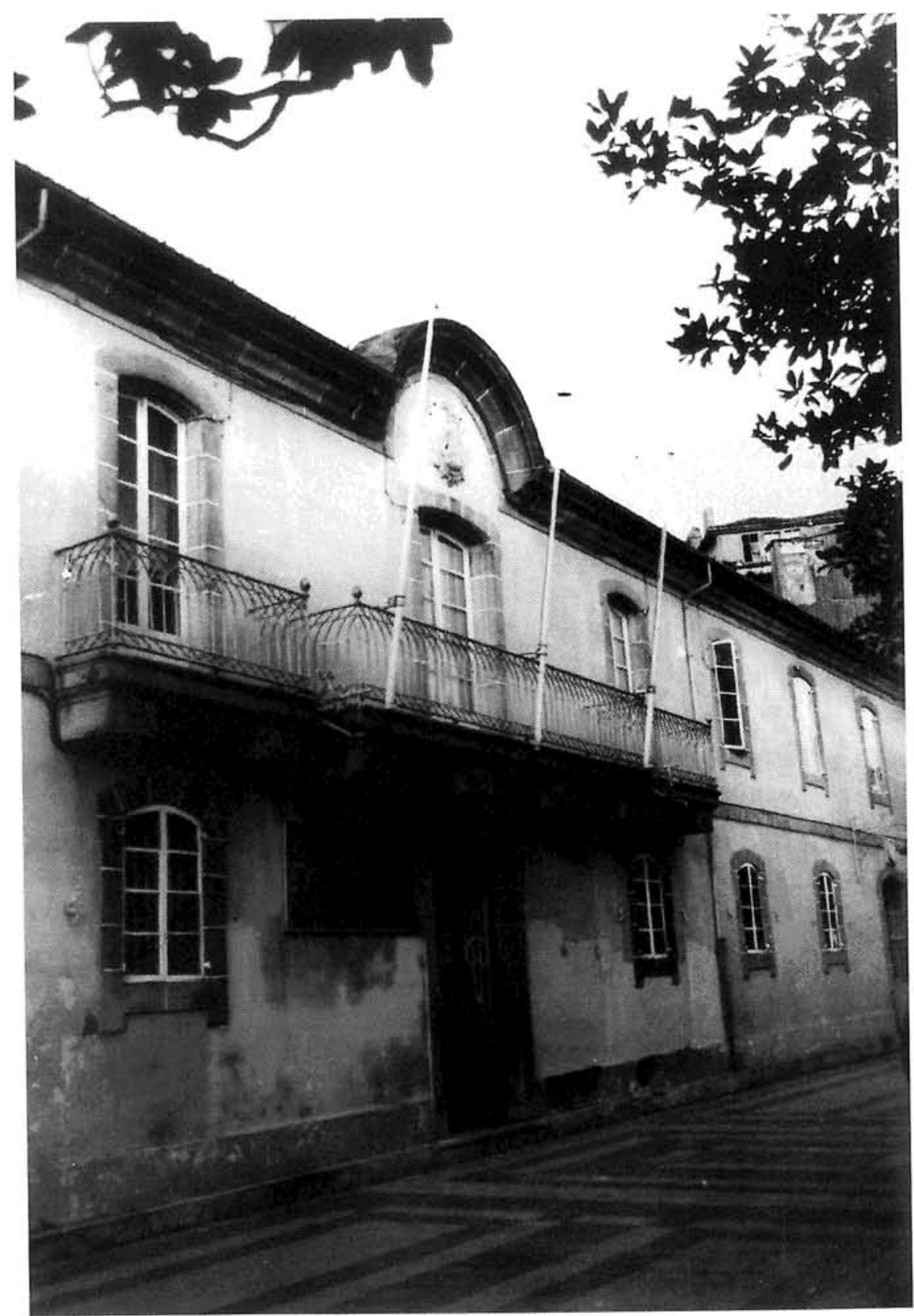

Fig.20.- Fachada principal de la Escuela de Gramática que durante mucho tiempo acogió al Ayuntamiento. Dionisio Sánchez Aguilera. 1786 (Demolida). 


\section{LA PLAZA DE LOS DOLORES Y LA CASA DEL SEÑOR GARCÍA FERNANDEZ}

El hecho de que hasta el 12 de octubre de 1793 todo el sector norte de la plaza de los Dolores estuviese exclusivamente reservado para instalar en él un edificio de carácter público y oficial bien destinado a Consistorio-Cárcel o a Cárcel con Sala de Justicia excluye, en todo caso, la posibilidad de que antes de esa fecha se pudiesen levantar allí edificios de otro tipo destinados a viviendas de propiedad particular. $Y$ viene al caso decir esto porque Montero Aróstegui, al hacer referencia al proyecto de Ayuntamiento elaborado por Sánchez de Aguilera en 1786, señalaba que «habia de formarse sobre arcadas....iguales a la de la casa del Sr. García Fernández y de otra proyectada por el Sr. Marqués de San Saturnino ${ }^{60}$. No hay duda que la casa en cuestión a la que Montero se refiere es la que, ya desaparecida $^{61}$, ocupaba el solar más occidental del sector de la plaza que se ha señalado, ya que su imagen la conocemos a través de un grabado decimonónico (Fig. 21) y de algunas fotografías de cronología más reciente (Fig. 3) ${ }^{62}$. Pero hay que decir que la posibilidad de que responda a la idea de Sánchez Aguilera es bastante improbable pues, aunque es cierto que se levantaba sobre pórticos y hay incluso a su lado otros que parecen responden a otra vivienda del mismo tipo que no se llegó a terminar (¿la casa del Marqués de San Saturnino?), éstas, en modo alguno, pudieron levantarse antes de 1794 y dada su fisonomía de arquitectura doméstica bien poco deben responder al plan de Aguilera que era, recuérdese, de 1786 y no

${ }^{60}$ MONTERO AROSTEGUI, 227. Su propietario D. Angel García Fernández con anterioridad, pero a finales del siglo XVIII, había entregado a la Municipalidad 6000 reales para abrir la calle que habría de pasar por el medio de la Plaza de los Dolores en dirección a la Calle del mismo nombre que es una de las principales que vertebran horizontalmente el Nuevo Ferrol.

${ }^{61}$ En sus últimos años acogió al Colegio «Tirso de Molina» de los Padres Mercedarios. Fue demolida entre 1938 y 1939 para dar paso al edificio actual propiedad asimismo de los PP. Mercedarios y obra proyectada por el destacado arquitecto Rodolfo Ucha Piñeiro. Vid. CASTELO ALVAREZ, 680-681.

${ }^{62}$ Aunque no tenemos ninguna prueba que lo certifique, nada tendría de particular que esta casa pudiese haber sido también diseñada por Fray Plácido Caamiña. La única conexión sería la noticia de que el Marqués de San Saturnino iba a levantar otra igual y que fue él, no lo olvidemos, junto con Juan Caamaño quienes conectaron con el benedictino para que diseñase el Consistorio ferrolano. Recuérdese, por otra parte, que Caamiña muere en 1812 .

"CUADERNOS DE ESTUdIOS GALLEGOS", Tomo XLII, Fascículo 107, Santiago 1995. 


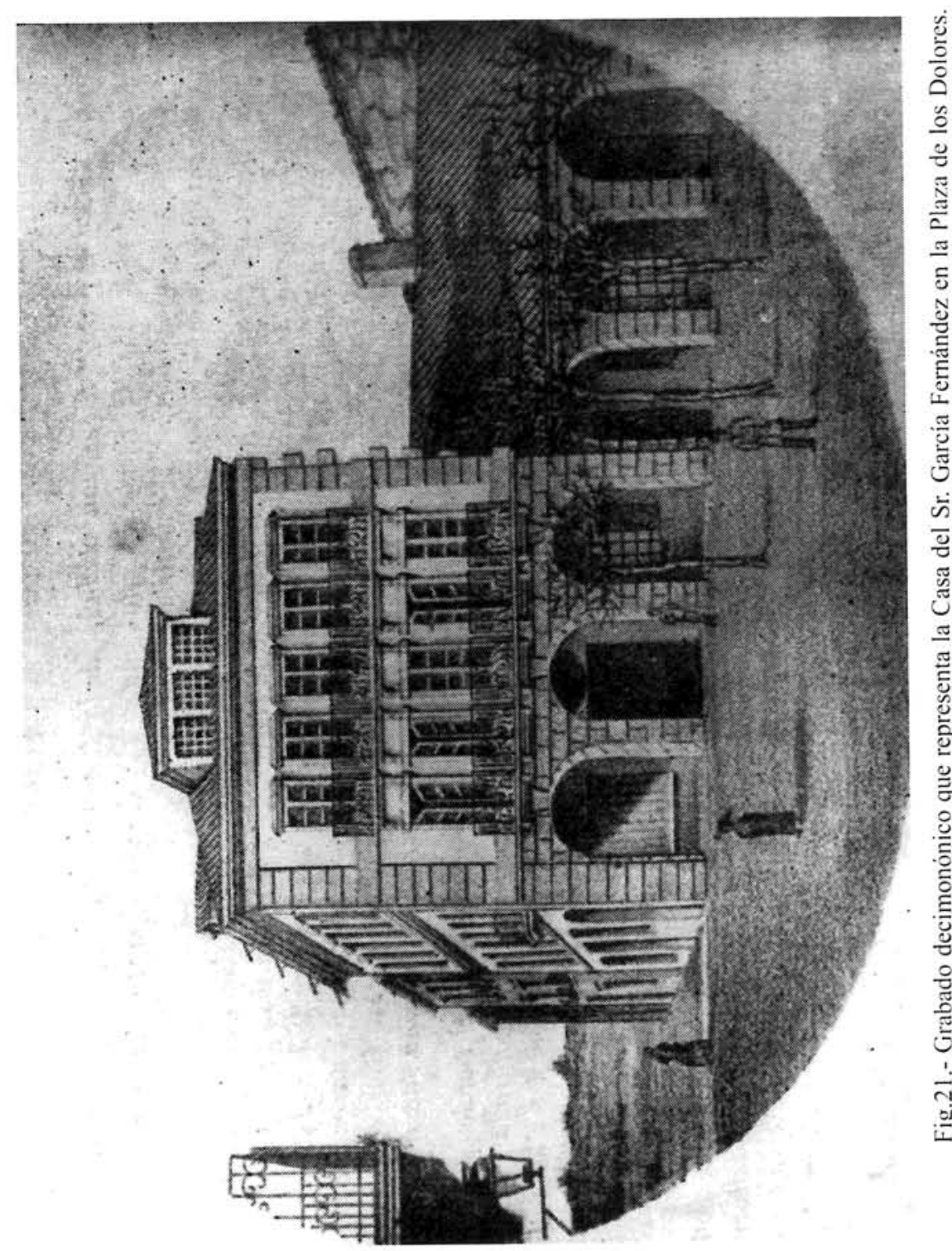


contemplaba ningún tipo de construcción residencial de carácter adosado. Necesariamente la Casa de García Fernández tuvo que levantarse después de 1794 en una fecha próxima al cambio de siglo o, mucho mejor, incluso en las primeras décadas del siglo XIX. Y debió erigirse, además, sometida seguramente a un plan ordenador que acaso promovió la propia Municipalidad una vez desistió de levantar en aquella zona un edificio de carácter público. Eso sí, con la condición expresa de que todos los frentes de las nuevas casas se ajustasen a un diseño común y porticado que perseguía el decoro y la homogeneidad de todo aquel sector ${ }^{63}$.

Tal práctica ordenadora, por otra parte, no debe olvidarse que es muy propia del tiempo al que hacemos referencia, y más si ésta se trataba de aplicar a un espacio de tanta cualificación como era el de una plaza regular que estaba, además, inmersa en el tejido de una población de nueva planta $^{64}$. La misma morfología arquitectónica de la Casa de García Fernández muy depurada y netamente clasicista habla también del tipo de arquitectura doméstica que solía diseñarse en este tiempo ${ }^{65}$. Por tanto, creo que bien se puede aceptar una filiación finisecular o de comienzos del XIX para la casa en cuestión que, de coincidir en algo con el proyecto de Aguilera, tendría que limitarse en exclusiva a que ambas construcciones estaban presididas por pórticos de carácter público en su zona inferior.

${ }^{63}$ No obstante, hacia 1867, BAAMONDE, 17 señala que «El frente (Norte) que forma la Plaza de los Dolores, cuenta solo con dos edificios a los extremos, que merezcan especial atención (uno de ellos la Casa de García Fernandez), siendo los demás ranchos pequeños, destinados actualmente a expendedurías de carne». El otro edificio a que se refiere el autor, también decimonónico, era el que, en 1867, acogía al Casino Ferrolano "cuyos jardines con su portada de piedra con verja, dan frente a la Plaza de los Dolores». Este último, por fortuna todavía existe con su noble fachada principal abierta a la Calle del Sol. Posteriormente fue sede del Hospicio Municipal. CASTELO ALVAREZ, 66 lo denomina «Mesón de Valentín» y dice que fue originariamente una construcción propiedad del Duque de Alba.

${ }^{64}$ Los ejemplos son numerosos; pero como más característicos pueden señalarse los que se plantearon para la Plaza Mayor de Ocaña en Toledo (1777), Vitoria (1782) y San Sebastián (1817).

${ }^{65}$ Ciertamente tiene una gran relación de parentesco con las ordenaciones urbanas que, referidas a calles o plazas regulares, proyectaron o erigieron entre el XVIII y XIX arquitectos como Silvestre Pérez, Olaguíbel, Nagusía, Ugartemendía o Martín de Saracíbar por poner algunos ejemplos. Vid. al respecto GAYA NUÑO; HERNANDO, 69 y ss. También NAVASCUES PALACIO (1993, II), 87 y ss.

"CUADERNOS DE ESTUDIOS GALLEGOS", Tomo XLII, Fascículo 107, Santiago 1995. 


\section{BIBLIOGRAFIA}

ARIAS, P.: «En torno al segundo centenario de un gran arquitecto gallego. Fray Plácido (Antonio) Camiña», Bol. de la Comisión Provincial de Monumentos de Lugo, II, 14-15, Lugo, 1945, pp. 180-182.

BAAMONDE Y ORTEGA, J.: Album pintoresco, geográfico, estadistico, histórico y descriptivo de la ciudad departamental maritima de Ferrol y sus inmediaciones, Ferrol, 1867.

BARREIRO FERNANDEZ, J.R.: «Abadologio del monasterio benedictino de San Martín Pinario en Santiago de Compostela (1607-1835)», Studia Monastica, Montserrat, 1965, pp. 147-188.

BELLINI, A.: Benedetto Alfieri, Milano, 1978.

BONET CORREA, A.: «Concepto de Plaza Mayor en España desde el siglo XVI hasta nuestros días», en Morfología y Ciudad. Urbanismo y arquitectura durante el Antiguo Régimen en España, Barcelona, 1978, pp. 35-64.

BOUZA BREY, F.(1944-45): «Monjes benedictinos maestros de obras en el Monasterio de San Martín Pinario», Cuadernos de Estudios Gallegos, IV, Santiago, 1944-45, pp. 663-672.

BOUZA BREY, F. (1945): «La patria de los maestros de obras benedictinos Fray Gabriel de las Casas y Fray Plácido Caamiña», Bol. de la Comisión Provincial de Monumentos de Lugo, II, 14-15, Lugo, 1945, pp. 35-36.

CAPEL, H. et al.: Los ingenieros militares en España. Siglo XVIII. Repertorio biográfico e inventario de su labor cientifica y espacial, Barcelona, 1983.

CARPENTE FERNANDEZ, A.: «Púlpitos y rejas de San Martín Pinario», en Galicia no Tempo 1991, Santiago, 1991, pp. 395-408.

"CUADERNOS DE ESTUDIOS GALLEGOS", Tomo XLII, Fasciculo 107, Santiago 1995. 
CASTELO ALVAREZ, B.: Ferrol: Morfología urbana y Arquitectura 1800-1936. Tesis Doctoral inédita dirigida por la profesora $\mathrm{M}^{2}$ Luisa Sobrino Manzanares en la Facultad de Geografia e Historia de la Universidad de Santiago en 1994.

CENDAN PAZOS, F.: El Ferrol: su ría y su comarca, Madrid, 1978.

CERVERA VERA, L.: El arquitecto gallego Domingo Lois Monteagudo (1723-1786) y su «Libro de Barios Adornos», La Coruña, 1985.

COUSELO BOUZAS, J.: Galicia artística en el siglo XVIII y primer tercio del XIX, Compostela, 1932.

CRESPO POZO, J.S.: Blasones y linajes de Galicia, II, Santiago, 1957.

CHAMOSO LAMAS, M.: La arquitectura barroca en Galicia, Madrid, 1955.

CHUECA GOITIA, F.: «La época de los Borbones», en Resumen histórico del urbanismo en España, Madrid, 1968, pp. 211-248.

FERNANDEZ FERNANDEZ, X.: Arquitectura del Eclecticismo en Galicia (1875-1914), La Coruña, 1995.

FERNANDEZ REY, A.A.: «Varios siglos de actividad constructiva en San Martín Pinario», en Galicia no Tempo 1991, Santiago, 1991, pp. 351-393.

FOLGAR DE LA CALLE, Ma DEL C.: Simón Rodríguez, La Coruña, 1989.

GARCIA-ALCAÑIZ YUSTE, J. (1986): Arquitectura neoclásica en Galicia. Siglos XVIII al XIX (Historia y Estética), 2 vols., Madrid, 1986.

GARCIA-ALCAÑIZ YUSTE, J. (1989): Arquitectura del Neoclásico en Galicia, La Coruña, 1989.

"CUADERNOS DE ESTUdiOS GALLEGOS", Tomo XLII, Fascículo 107, Santiago 1995. 
GAYA NUÑO, J.A.: Arte del siglo XIX, Ars Hispaniae, XIX, Madrid, 1958.

GONZALEZ RODRIGUEZ, P.J.: «La capilla de los Dolores de Ferrol. Historia de su construcción», Estudios Mindonienses, Ferrol, 1989, pp. 663-691.

GUILLEN MARCOS, E. (1989): «La fortuna de un arquitecto pensionado en Roma: Domingo Lois Monteagudo», Academia, n 69, Madrid, 1989, pp. 181-205.

GUILLEN MARCOS, E. (1990): De la Ilustración al Historicismo: Arquitectura religiosa en el Arzobispado de Granada (1773-1868)», Granada, 1990.

HERNANDO, J.: Arquitectura en España. 1770-1900, Madrid, 1989.

LOPEZ VAZQUEZ, J.M.(1990,I): «Retablo de Santa Escolástica», en Galicia no Tempo, Santiago, 1990, pp. 335-336.

LOPEZ VAZQUEZ, J.M. (1990,II): «Retablo de Santa Gertrudis. La Magna», en Galicia no Tempo, Santiago, 1990, pp. 337-338.

LOPEZ VAZQUEZ, J.M. (1990,III): «Cristo de la Paciencia», en Galicia no Tempo, Santiago, 1990, pp. 338-339.

MADOZ, P.: Diccionario geográfico-estadístico-histórico de España y sus posesiones de Ultramar, VIII, Madrid, 1850.

MARTIN-MERAS, L. Y RIVERA, B.: Catálogo de cartografia histórica de España del Museo Naval, Madrid, 1990.

MARTINEZ SUAREZ, X.L.: A praza de María Pita. A Coruña (18591959), Santiago, 1993.

MONTERO AROSTEGUI, J.: Historia y descripción de El Ferrol, Ferrol, 1858. Cit. por la edición publicada en Puentedeume, 1972.

"CUADERNOS DE ESTUdIOS GALLEGOS", Tomo XLII, Fascículo 107, Santiago 1995 
MONTERROSO MONTERO, J.M.: «Apuntes sobre el monumento de Jueves Santo de San Martín Pinario», en Galicia no Tempo 1991, Santiago, 1991, pp. 409-427.

MURGUIA, M.: El arte en Santiago en el siglo XVIII, Madrid, 1884.

NAVASCUES PALACIO, P. (1993, I): La plaza mayor en España, Madrid, 1993.

NAVASCUES PALACIO, P. (1993, II): Arquitectura Española (18081904), Summa Artis, XXXV, Madrid, 1993.

ORTEGA ROMERO, M ${ }^{\mathrm{a}}$ DEL S. (1966): «Noticias sobre la construcción del Ayuntamiento de Santiago de Compostela», Cuadernos de Estudios Gallegos, Santiago, 1966, pp. 81-101.

ORTEGA ROMERO, Ma DEL S. (1970): «El arquitecto Miguel Ferro Caaveiro», Cuadernos de Estudios Gallegos, XXV, Santiago, 1970.

ORTEGA ROMERO, Ma DEL S. (1974): «Ferro Caaveiro, Miguel», en Gran Enciclopedia Gallega, XII, Santiago, pp. 157-162.

OTERO TUÑEZ, R. (1951): «Un gran escultor del siglo XVIII: José Ferreiro», Archivo Español de Arte, XXIV, Madrid, 1951, pp. 35-47.

OTERO TUÑEZ, R. (1953): «El estilo y algunas esculturas de Ferreiro», Archivo Español de Arte, XXVI, Madrid, 1953, pp. 51-62.

OTERO TUÑEZ, R. (1958): «El barroco italiano en la obra de José Ferreiro», Bol de la Universidad Compostelana, Santiago, 1958, pp. 95-111.

PEVSNER, N.: Historia de las tipologias arquitectónicas, Barcelona, 1979.

RODRIGUEZ-VILLASANTE Y PRIETO, J.A.: Historia y tipologia arquitectónica de las defensas de Galicia. Funcionalidad, forma y ejecución del diseño clasicista, Sada, 1984.

SA BRAVO, H.DE: El Monasterio de San Martín Pinario, León, 1988.

"CUADERNOS DE ESTUDIOS GALLEGOS", Tomo XLII, Fascículo 107, Santiago 1995. 
SAMBRICIO, C. (1982): «El urbanismo de la Ilustración: 1750-1814», en Vivienda y urbanismo en España, Madrid, 1982, pp. 137-157.

SAMBRICIO, C. (1991): Territorio y ciudad en la España de la Ilustración, Madrid, 1991.

SERLIO, S.: Tutte l'Opere d'Architettura et prospetiva, Venecia, 1600.

SORALUCE BLOND, J.R.: Castillos y fortificaciones de Galicia, La Coruña, 1985.

TARRAGO CID, S.; VIGO TRASANCOS, A. y RODRIGUEZVILLASANTE Y PRIETO, J.A.: El Barrio de La Magdalena del Ferrol, Santiago, 1980.

TORREJON CHAVES, J.: La nueva población de San Carlos en la Isla de León, 1774-1806, Madrid, 1992.

VIGO TRASANCOS, A. (1984): Arquitectura y urbanismo en el Ferrol del siglo XVIII, Santiago, 1984.

VIGO TRASANCOS, A. (1989, I): «Domingo Lois Monteagudo y su propuesta neoclásica de Pazo Gallegon, en Los Caminos y el Arte, Actas del VI Congreso Español de Historia del Arte, II, Santiago, 1989, pp. 381-392.

VIGO TRASANCOS, A. (1989, II): «Domingo Lois Monteagudo y la Capilla de la Comunión de la Catedral Compostelana (1764-1783)», Bol. del Seminario de Estudios de Arte y Arqueología, Valladolid, 1989, pp. 450-466.

VIGO TRASANCOS, A. (1992, I): «La intervención del Estado dieciochesco en la arquitectura gallega de iniciativa privada: El papel de los ingenieros y la obra de Carlos Lemaury, Cuadernos de Estudios Gallegos, XL, Santiago, 1992, pp. 103-133. 
VIGO TRASANCOS, A. (1992, II): «La arquitectura en Santiago a mediados del siglo XVIII: La década de 1760 y la introducción del Academicismo», en Actas del Congreso Internacional da Cultura Galega, Santiago, 1992, pp. 13-24.

VIGO TRASANCOS, A. (1995): La Arquitectura de la Ilustración. Clasicismo y Neoclasicismo. 1700-1834. Biblioteca Coruñesa, La Coruña, 1995.

"CUAdERnOS DE ESTUdiOS GAllegOS", Tomo XLII, Fascículo 107, Santiago 1995. 